\title{
Extinction of Learned Fear Induces Hippocampal Place Cell Remapping
}

\author{
Melissa E. Wang, ${ }^{1 \star}$ Robin K. Yuan, ${ }^{1 \star}$ Alexander T. Keinath, ${ }^{1}$ Manuel M. Ramos Álvarez, ${ }^{2}$ and Isabel A. Muzzio ${ }^{1}$ \\ ${ }^{1}$ Department of Psychology, University of Pennsylvania, Philadelphia, Pennsylvania 19104 and ${ }^{2}$ Department of Psychology, Universidad de Jaén, 23071 \\ Jaén, Spain
}

The extinction of learned fear is a hippocampus-dependent process thought to embody new learning rather than erasure of the original fear memory, although it is unknown how these competing contextual memories are represented in the hippocampus. We previously demonstrated that contextual fear conditioning results in hippocampal place cell remapping and long-term stabilization of novel representations. Here we report that extinction learning also induces place cell remapping in C57BL/6 mice. Specifically, we observed cells that preferentially remapped during different stages of learning. While some cells remapped in both fear conditioning and extinction, others responded predominantly during extinction, which may serve to modify previous representations as well as encode new safe associations. Additionally, we found cells that remapped primarily during fear conditioning, which could facilitate reacquisition of the original fear association. Moreover, we also observed cells that were stable throughout learning, which may serve to encode the static aspects of the environment. The short-term remapping observed during extinction was not found in animals that did not undergo fear conditioning, or when extinction was conducted outside of the conditioning context. Finally, conditioning and extinction produced an increase in spike phase locking to the theta and gamma frequencies. However, the degree of remapping seen during conditioning and extinction only correlated with gamma synchronization. Our results suggest that the extinction learning is a complex process that involves both modification of pre-existing memories and formation of new ones, and these traces coexist within the same hippocampal representation.

Key words: conditioning; extinction; gamma coherence; place cells; predator odor; stability

\section{Introduction}

The extinction of learned fear, when a conditioned fear response is reduced or eliminated as a result of weakening of the conditioned association, is generally thought of as new learning rather than erasure of a fearful memory. This is primarily attributable to behavioral experiments that identified several processes wherein the conditioned fear response resurfaces after extinction. Notably, the conditioned response returns when a delay (spontaneous recovery) or a mild unconditioned stimulus (reinstatement) is introduced after extinction training, or when extinction is tested outside of the context where training occurred (contextual renewal; Myers and Davis, 2002; Bouton, 2004; Ji and Maren, 2007). Thus, it is thought that fear extinction results in a novel memory trace that competes with the original fear memory. The contextual specificity of extinction suggests that the hippocampus is critical for this process (Corcoran and Maren, 2004; Corc-

Received Oct. 28, 2014; revised April 14, 2015; accepted May 6, 2015.

Author contributions: I.A.M. designed research; M.E.W. and R.K.Y. performed research; M.E.W., R.K.Y., A.T.K., M.M.R.A., and I.A.M. analyzed data; M.E.W., R.K.Y., and I.A.M. wrote the paper.

This work was supported by the National Science Foundation (NSF) CAREER award to I.A.M. (1256941), a Ruth L. Kirschstein National Research Service Award to R.K.Y. (1F31MH105161-01A1), and an NSF IGERT fellowship to A.T.K.

${ }^{*}$ M.E.W. and R.K.Y. contributed equally to this work.

The authors declare no competing financial interests.

Correspondence should be addressed to Isabel A. Muzzio, Department of Psychology, 3720 Walnut Street, D5 Solomon Lab Building, Philadelphia, PA 19104-6241. E-mail: imuzzio@sas.upenn.edu.

DOI:10.1523/JNEUROSCI.4477-14.2015

Copyright $\odot 2015$ the authors $\quad 0270-6474 / 15 / 359122-15 \$ 15.00 / 0$ oran et al., 2005; Ji and Maren, 2005). However, it is unknown how the hippocampus encodes these conflicting emotional representations.

The most striking evidence for the role of the hippocampus in spatial processing comes from the activity of its principal neurons, known as place cells, which fire in selective locations as an animal traverses a context (O'Keefe and Dostrovsky, 1971) and are thought to encode a neural representation of space (O'Keefe and Nadel, 1978). Recently, it has been shown that hippocampal place cells remap in response to fear learning (Moita et al., 2004), and this novel representation stabilizes in the long term (Wang et al., 2012). However, the physiological responses of these neurons to extinction learning are unknown. Since place cell stability is thought to be a neural correlate of spatial memory (Rotenberg et al., 1996, 2000; Kentros et al., 1998; Agnihotri et al., 2004), our previous results showing place field stabilization after conditioning provide a unique basis for understanding hippocampal encoding of extinction. These findings allow us to evaluate how stable fear representations are affected by changes in the emotional valence of a context.

Place cells can represent multiple aspects of the same context in accordance with varying reference frames such as tasks and motivations (Gothard et al., 1996; Zinyuk et al., 2000; Ferbinteanu and Shapiro, 2003). Thus, it is possible that place cells may also encode different emotional representations of fear and safety. To assess this possibility, it is necessary to record from the 
same neurons throughout fear learning. To this end, we developed an extinction paradigm using predator odor contextual fear conditioning. We found that extinction produces remapping in some cells, indicating that a new "safe" contextual representation is formed. This remapping occurs in a subset of cells that previously remapped during fear conditioning and a subset that was primarily stable during encoding of the fear association, suggesting that extinction may both modify old memory traces and lead to the formation of new ones. Interestingly, some cells remain stable throughout fear learning and extinction, which suggests that these cells mainly respond to the static aspects of the spatial context rather than changes in valence. Finally, during extinction, there is an increase in low $(30-60 \mathrm{~Hz})$ and high $(60-80 \mathrm{~Hz})$ gamma coherence, a synchronization mechanism involved in signal amplification that has been shown to correlate with attentional processes (Womelsdorf and Fries, 2006). These results indicate that the neural correlates of extinction include a complex spatial representation that incorporates distinct traces of varying emotional valence, and processing of these traces may be enhanced through increases in gamma synchronization.

\section{Materials and Methods}

Subjects. Male mice 2-6 months of age (strain: C57BL/6; The Jackson Laboratory) were housed individually on a $12 \mathrm{~h}$ light/dark cycle and allowed access to food and water ad libitum. All experiments were performed in accordance with NIH guidelines and approved by the Institution of Animal Care and Use Committee of the University of Pennsylvania.

Training of extinction and control animals during behavioral and electrophysiological testing. To evaluate the influence of extinction on hippocampal place cells, we devised an extinction paradigm based on our previously reported predator odor contextual fear-conditioning paradigm (Wang et al., 2013). Mice were pre-exposed to the rectangular training context $(30 \mathrm{~cm} \times 40 \mathrm{~cm})$ in two 10 min sessions, both $24 \mathrm{~h}$ and immediately before contextual fear conditioning (habituation and baseline sessions). Fear conditioning was then conducted by returning mice to the training context for $5 \mathrm{~min}$ while a paper towel square $(2.5 \mathrm{~cm} \times 2.5$ $\mathrm{cm}$ ) saturated with 40 drops of $100 \%$ coyote urine (Maine Outdoor Solutions) was taped to the center of the context. Ten minute retrieval tests were given at 1 and $24 \mathrm{~h}$ after conditioning. Immediately after the $24 \mathrm{~h}$ memory retrieval test, mice undergoing extinction were exposed to the same context for $30 \mathrm{~min}$ to extinguish fear learning. A retrieval test 10 min in length was conducted $24 \mathrm{~h}$ post extinction ( $48 \mathrm{~h}$ after coyote urine exposure). Since we were interested in testing extinction, we used a larger amount of coyote urine than we previously reported during conditioning (Wang et al., 2012) and introduced a learning criterion to ensure that all animals included in the analysis displayed consistent and robust learning. Specifically, only animals showing at least a $20 \%$ increase in freezing at $24 \mathrm{~h}$ were included in the extinction group. One animal did not reach the learning criteria and was excluded from the analysis.

To test the context specificity of extinction for predator odor fear conditioning, a third group of mice (ABA control) was conditioned in the training context (A), extinguished in a novel context (B), and tested $24 \mathrm{~h}$ after extinction training in context A. To control for repeated contextual exposure and to rule out nonassociative effects, another group of mice (water control) was placed in the context following the same schedule as the extinction animals (including the 30 min extinction session), but was not fear conditioned with the odor.

For electrophysiological experiments, the extinction, water control, and ABA groups were run as described above. Additionally, to evaluate the effect of an aversive, nonfearful odor on place cell representations, we added short-term and long-term odor controls. The short-term controls included three groups of mice that were exposed to water, coyote urine, or 2-methylbutyric acid (2-MB), a synthetic odor resembling the smell of spoiled food, in a context with no visual cues to assess electrophysiological responses in the presence and absence of the odors. The long-term odor control group consisted of a subset of animals following the same schedule as the extinction group that were exposed to 2-MB instead of coyote urine during the conditioning session. We had previously shown that this odor does not produce long-term freezing to the context (Wang et al., 2013), and here we evaluated if it had some short- and/or long-term effects on place cell representations during extinction. In all sessions, freezing was measured as an index of fear learning. Freezing was defined as a period of total immobility except for respiratory movements and computed as the percentage of time during which the velocity of the animal was lower than $0.6 \mathrm{~cm} / \mathrm{s}$. Freezing was measured using two independent measures including the automated Limelight system (Coulbourn Instruments) and custom-written MATLAB code. The position data were smoothed with a $1 \mathrm{~s}$ boxcar before the assessment of freezing to eliminate jitter in the tracking.

Surgery. Mice were anesthetized with a mixture of ketamine $(100 \mathrm{mg} /$ $\mathrm{kg})$ and xylazine $(10 \mathrm{mg} / \mathrm{kg})$ administered intraperitoneally and placed into a stereotaxic frame (David Kopf Instruments). They were then implanted with drivable 6-tetrode microdrives above the dorsal hippocampus [from bregma (in mm): AP, $-1.7 ; \mathrm{ML},-1.6$; DV, -1.0]. A ground wire was connected to a screw placed on the contralateral side of the skull. The headstages were affixed to the skulls with cyanoacrylate and dental cement.

Electrophysiology and data analysis. Electrophysiology and data analysis were done as previously described (Wang et al., 2012). Beginning 1 week after surgery, neural activity from each tetrode was screened daily. The search for cells was conducted in an environment different from the one used for actual experiments. The headstage was connected to a tethered unity gain amplifier with green and red LEDs for tracking the position of the animal. Units were amplified using a 32-channel amplifier between 2500 and 10,000 times and filtered between 400 and $9000 \mathrm{~Hz}$. The amplifier output was digitized at $30.3 \mathrm{kHz}$. The position of the animal and electrophysiological data were recorded by Cheetah Data Acquisition software (Neuralynx). The electrode bundle was advanced by $15-20 \mu \mathrm{m}$ steps per day, lowering the tetrodes in small steps to increase the stability of the recordings (Kentros et al., 2004; Muzzio et al., 2009) until pyramidal cells were identified by their characteristic firing patterns (Ranck, 1973). Experiments were begun only when recordings were stable for at least $24 \mathrm{~h}$. Long-term recordings were considered stable when cells had the same cluster boundaries over two sessions, and the waveforms obtained from all four wires of a tetrode were identical between sessions.

After completion of the experiments, units were cluster cut and analyzed using MClust software (developed by A. David Redish, University of Minnesota). Cells were only accepted for analysis if they formed isolated clusters with clear Gaussian ellipses and minimal overlap with surrounding cells and noise, and displayed high waveform similarity throughout the experiment. To ensure that the quality of our clusters was similar in both groups over time, we computed isolation distance, a measure of how separated a cluster is from other spikes recorded on the same tetrode (Harris et al., 2001; Schmitzer-Torbert et al., 2005). The isolation distance parameter reflects the radius of the smallest ellipsoid from the center of the cluster under study to noise or other spikes, and we used this measure to compare cluster quality between groups in all sessions. Finally, all cells were inspected to rule out events during the $2 \mathrm{~ms}$ refractory period.

The generation of place field maps was done in MATLAB by first dividing the environment into $2 \times 2 \mathrm{~cm}$ pixels, then calculating the number of spikes and the time spent in each pixel. Both the spike count and time maps were then smoothed with a $3 \mathrm{~cm}$ full-width at halfmaximum Gaussian kernel. The final place field map was obtained by dividing the smoothed spike map by the smoothed rate map. Only periods of movement were included in the place field analysis, during which the minimum walking speed was $2 \mathrm{~cm} / \mathrm{s}$. We excluded cells that fired $<40$ spikes during movement in a session or displayed peak firing frequencies $<1.3 \mathrm{~Hz}$ before smoothing after the speed threshold was applied. Sampling of the environment was calculated as the percentage of pixels sampled for $>1 \mathrm{~s}$ after smoothing. Place field stability was assessed by performing pixel-by-pixel Pearson R cross-correlations between maps.

To evaluate whether the remapping observed during extinction occurred gradually, we divided the extinction session in three consecutive 
blocks, extinction 1-3 (ext1, ext2, and ext3), and performed pixel-bypixel cross-correlations between these blocks. To visualize the remapping trends in the data and to determine which cells were more stable than chance, we established a correlation threshold of 0.3 using the following randomization procedure. For each animal, place field maps were generated for the $24 \mathrm{~h}$ session and the last block of extinction (ext3). Next, the map of each cell from the $24 \mathrm{~h}$ session was correlated with a random map from the ext 3 session, and the mean correlation across comparisons was computed. These random correlations were computed 1000 times with replacement, e.g., for each animal, a particular cell participated in more than one random comparison. This procedure yielded a distribution of mean random correlation values for each animal. The highest $95 \%$ value of these distributions ( 0.3 ) was chosen as remapping threshold to guarantee that stability values above this were significant with a 0.05 probability level (data not shown). Cells with a pixel-by-pixel crosscorrelation below this threshold over the course of conditioning or extinction training sessions were considered to exhibit remapping in response to these learning processes. This correlation threshold corresponds with previous studies in mice showing place field stability (Kentros et al., 2004; Muzzio et al., 2009), but it does not have a direct physiological correlate. Therefore, it is used here only to capture remapping trends in the data and describe the cellular phenotypes that emerge during extinction.

A place field was defined as activity within nine or more contiguous pixels (total area $\geq 36 \mathrm{~cm}^{2}$ ). Place field size was calculated as the total area of the pixels comprising a field. If more than one place field was present, place field size was calculated as the average of all fields. Mean firing rate was calculated as the number of spikes during movement divided by the amount of time the animal was moving. Place field coherence, a measure of field organization, was calculated by correlating each pixel with its eight neighboring pixels, before smoothing. The spatial information content for cell $i$ was calculated as previously described (Skaggs et al., 1993) using the formula IC $=\sum p_{i}\left(R_{i} / R\right) \log \left(R_{i} / R\right)$, where $p_{i}$ is the probability of occupying pixel $i, R_{i}$ is the firing rate at location $i$, and $R$ is the overall mean firing rate.

Spike synchronization analysis. The local field potential (LFP) signal was recorded from tetrodes used to obtain single-unit activity. These data were recorded at $30 \mathrm{kHz}$, digitally filtered between 0.1 and $400 \mathrm{~Hz}$. For further processing, data were imported to MATLAB, then low-pass filtered and resampled to $10 \mathrm{kHz}$ using the MATLAB function, resample, to reduce the size of data files and make further analysis computationally tractable. We used these data to analyze spike-field coherence (SFC), a measure of phase synchronization between the LFP and spike times as a function of frequency (Fries et al., 2001). To this end, we first calculated the spike-triggered average (STA) by extracting the LFP segment \pm 500 $\mathrm{ms}$ around each spike and averaging across these spike-triggered epochs. In the absence of neuronal synchronization the STA would be flat, whereas when spikes are phase locked to particular frequencies, a signal at these frequencies can be observed in the STA. We then estimated the power spectrum using the multitaper method (MATLAB function pmtm), over the range of $4-80 \mathrm{~Hz}$ in log increments. To calculate SFC, the power spectrum of the STA was divided by the average of all power spectra of the spike-triggered epochs. We computed normalized coherence spectra showing the change in SFC for all frequencies (mean \pm 1 SEM), without binning in frequency bands. Coherence spectra were normalized by the coherence during the baseline session for each cell. Additionally, we examined coherence in theta $(4-12 \mathrm{~Hz})$, low gamma (40-60 $\mathrm{Hz})$, and high gamma $(60-80 \mathrm{~Hz})$ frequency bands by averaging the coherence spectra in these bands. Finally, we correlated the coherence in these frequency bands with place field stability, averaging across all cells within a session, to assess the relationship between remapping and synchrony in these bands. Place field stability was Fisher transformed before these correlations to reduce any potential ceiling effects.

Statistics. A two-way ANOVA with repeated measures was used to compare freezing between extinction and control animals across all sessions of conditioning or extinction. Statistical analyses of place cell correlations and gamma coherence were performed with a mixed-models approach (McCulloch and Searle, 2001) based on our previously reported statistical analyses (Wang et al., 2012). Post hoc multiple compar- isons were conducted using Bonferroni corrections. Although no details are included, all statistical decisions in the overall analyses and post hoc multiple comparisons were confirmed by additional robust and conservative mixed models and nonparametric tests. These additional statistical analyses allow conservative statistical decisions because they do not depend on the fulfillment of assumptions inherent to parametric tests or the possible presence of outliers.

In all mixed-model analyses, we first tested group by session interactions. If there was a significant interaction, we tested for simple effects of group on each individual session or session on extinction group using maxT multiple-comparison tests for mixed-model estimates (Maxwell and Delaney, 2004) to control for type I error. If there was no significant interaction, we conducted post hoc tests for main effects of group. All mixed-model analyses were performed using GNU R software (R Foundation for Statistical Computing) with nlme, lme4, multcomp, contrast, lmerTest, nparLD, and nparcomp libraries. In all cases, a significant difference was determined with a probability $<0.05$. Fisher-transformed correlations were used to determine the relationship between remapping and theta and gamma coherence.

\section{Results}

Prolonged exposure to the training context produces contextspecific extinction of predator odor fear

To examine the effects of fear extinction at the behavioral level, we tested three independent groups of animals. The extinction and ABA control groups were fear conditioned as previously reported in our predator odor contextual fear-conditioning study (Wang et al., 2013). These groups later underwent contextual extinction by exposure to either the training context (extinction) or a novel context (ABA control) for $30 \mathrm{~min}$. The extinction group tested if a prolonged exposure to the training environment decreased fear to the context and the ABA group tested if predator odor extinction learning was context specific, as previously demonstrated in other extinction paradigms (Bouton, 2004; Ji and Maren, 2007). The third group (water control) was tested in a single context following the same schedule as the other groups, but was exposed to water rather than coyote urine during the conditioning session. This group controlled for possible nonassociative effects such as habituation. All groups were then retested in the context $24 \mathrm{~h}$ after extinction (postext session; Fig. $1 A$ ). As an index of fear, percentage of total time spent freezing was measured in all trials. It has previously been shown that a prolonged exposure to the conditioning context extinguishes the conditioned fear response for shock-induced fear (Suzuki et al., 2004; Mamiya et al., 2009); here, we found that similar extinction training also produces predator odor fear extinction. Specifically, we observed that the prolonged exposure to the training context reduced freezing $24 \mathrm{~h}$ after extinction (postext session) while the same length of exposure to a novel context (ABA group) did not. Additionally, repeated exposures to the context (water control) did not significantly affect freezing at any time point (effect of group: $F_{(2,29)}=4.86, p<0.015$; effect of session: $F_{(4,112)}=10.07$, $p<0.001$; interaction: $F_{(8,112)}=2.52, p<0.015$; post hoc tests indicated that freezing in both the extinction and ABA control groups was significantly higher than the water control during the 1 and 24 h sessions, while in the postext session only freezing in the ABA control was significantly higher than the water control, $p<0.036$; Fig. $1 B$ ). Furthermore, the freezing observed in the extinction group $24 \mathrm{~h}$ after extinction was not significantly different from baseline freezing levels $(p>0.05)$, indicating that the 30 min extinction session was sufficient to extinguish behavioral fear responses. 


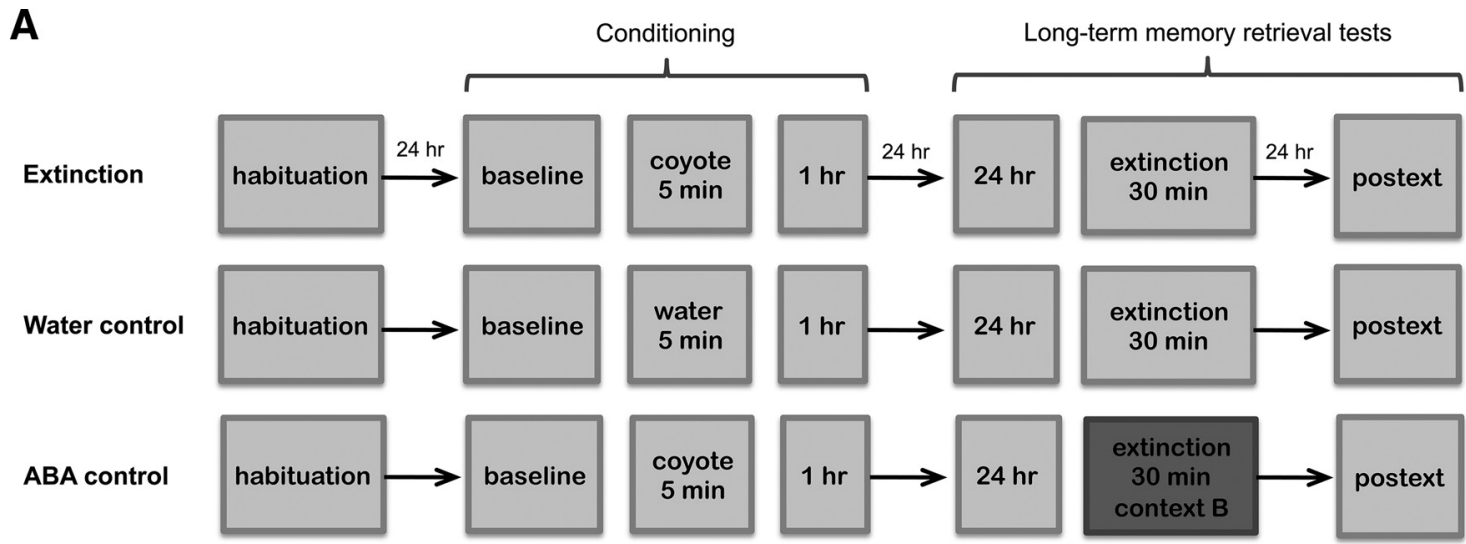

B

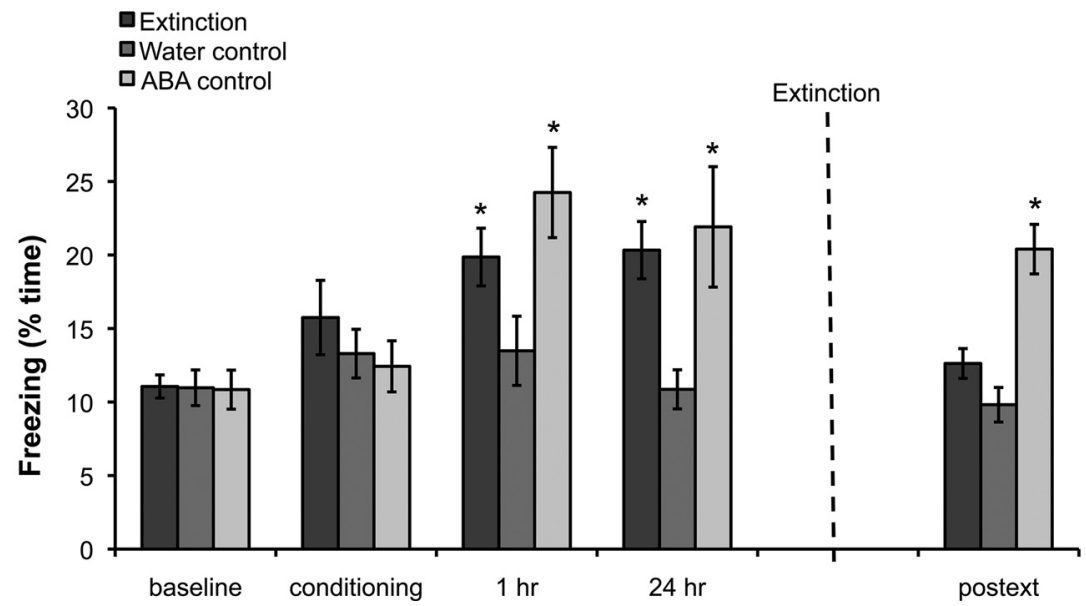

Figure 1. A, Schematic representation of behavioral paradigm. $\boldsymbol{B}$, In extinction animals, freezing returns to baseline levels $24 \mathrm{~h}$ after extinction (postext). Animals exposed only to the context (water control) following the same schedule as the extinction animals do not display significant changes in freezing throughout training. Animals fear conditioned in the training context but exposed to a new context during extinction (ABA control) display fear in the training context when tested $24 \mathrm{~h}$ after extinction (extinction: $n=17$, water control: $n=12, A B A$ control: $n=7)$. Bars represent means \pm SEM, ${ }^{*} p<0.05$.

Cellular and behavioral characteristics during periods of movement are equivalent between extinction and water control animals

To examine the neural correlates of extinction, we recorded 107 cells from the dorsal area CA1 of five animals, of which 74 cells were held throughout training. As a control, we recorded from 40 cells in three animals run in the water control condition described previously, of which 35 cells were held throughout training (Fig. $2 A$ ). Cells accepted for analysis formed distinct clusters and exhibited stable waveforms and cluster boundaries between consecutive sessions (Fig. 2B). Additionally, there were no differences in mean isolation distance between clusters from each group at the beginning and end of training ( $t$ tests between groups: baseline $t_{(158)}=0.16, p>0.05 ; 24$ h postext $t_{(148)}=0.57, p>0.05$; Fig. $2 C)$, indicating that cell quality was similar across conditions.

We found that the electrophysiology animals undergoing extinction displayed the same freezing patterns observed in the extinction group shown in Figure $1 B$ [mean percentage freezing at baseline (bl): $13.94 \pm 1.29 ; 24$ h: $26.02 \pm 4.83$; postext: $13.09 \pm$ 1.34]. Importantly, the moderate differences in freezing between control and extinction animals did not affect sampling of the arena. All animals included sampled at least $75 \%$ of the context in all sessions, with no difference in mean sampling between groups $t_{(7)}=0.88, p>0.05$, mean sampling across sessions: extinction $97.5 \pm 0.01 \%$; control $97.8 \pm 0.02 \%$; Fig. $3 A$ ). Importantly, there were no differences in average speed (including periods of move- ment $>2 \mathrm{~cm} / \mathrm{s}$, the speed threshold used for place cell analyses) between the two groups across all sessions [no effect of group: $F<1$; session: $F_{(6,42)}=1.06, p>0.05$ or interaction: $F_{(2,42)}=$ $1.16, p>0.05$; mean across all sessions $(\mathrm{cm} / \mathrm{s})$ : extinction: $5.72 \pm$ 0.31; control: $5.98 \pm 0.32$; data not shown]. Additionally, there were no differences between the groups in the percentage of data included in the analyses (e.g., mean percentage of spikes firing during periods of movement across all sessions: extinction $67 \pm$ $4.4 \%$; control $65 \pm 3.5 \%$; $t_{(7)}=0.17, p>0.05$; data not shown).

\section{Differential remapping of place cells was observed in} response to emotional valence and static aspects of the context

At the cellular level, we found a high degree of variability in the stability of place fields during the short-term conditioning and extinction sessions. The majority of cells remapped in response to predator odor exposure during fear conditioning (cond), at $1 \mathrm{~h}$ later, or both sessions as previously shown (Wang et al., 2012). The cellular representations in the extinction group stabilized at the $24 \mathrm{~h}$ session (Fig. 3B-E), whereas the water control group (Fig. $3 F$ ) displayed the typical long-term remapping observed under no task contingencies (Kentros et al., 2004; Muzzio et al., 2009). Many place fields also appeared to shift during the extinction session (Fig. 3B,C), although some remained stable throughout extinction (Fig. $3 D, E$ ). Among the cells that remained stable during extinction, some remapped more strongly 
A

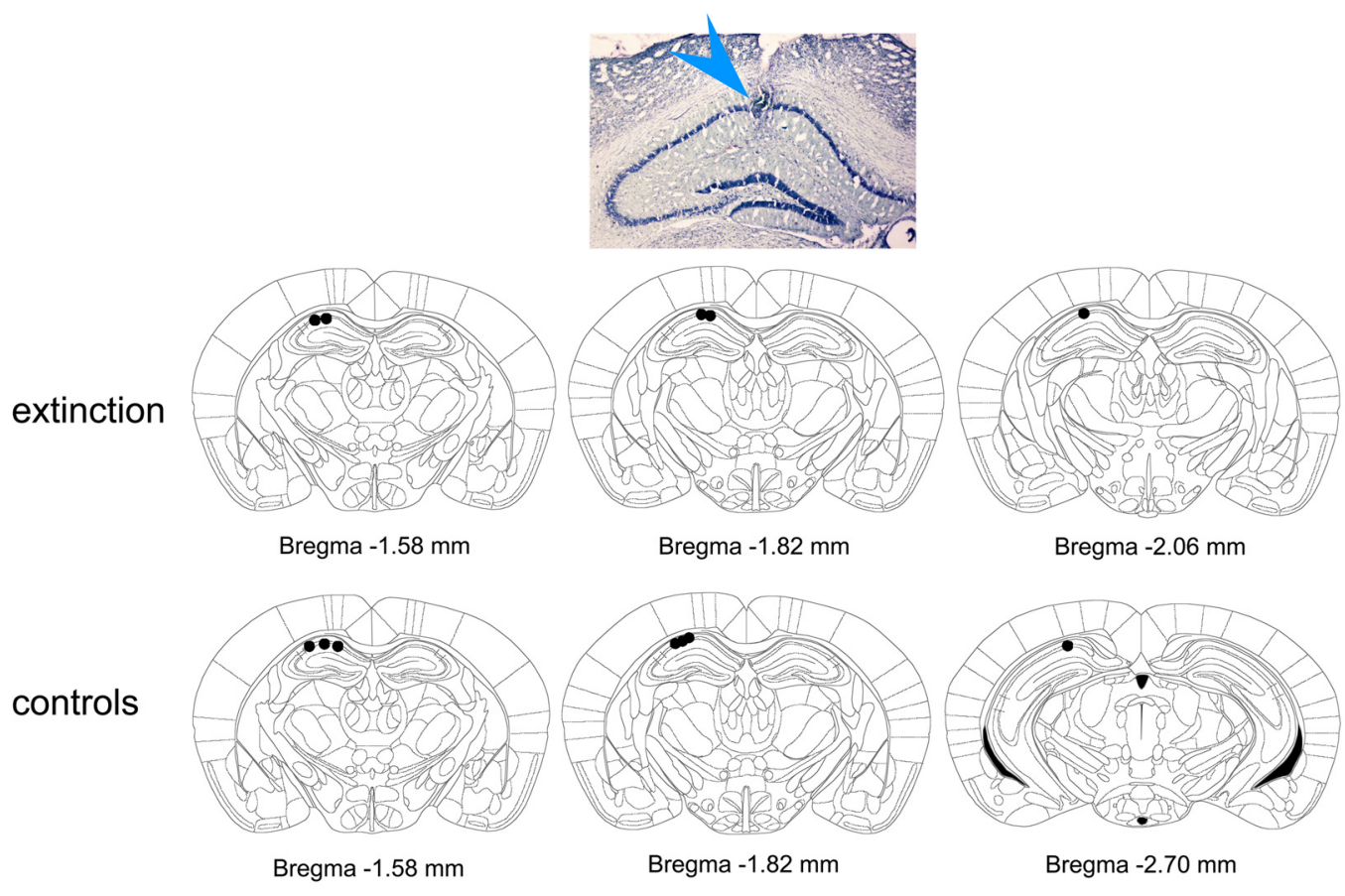

B
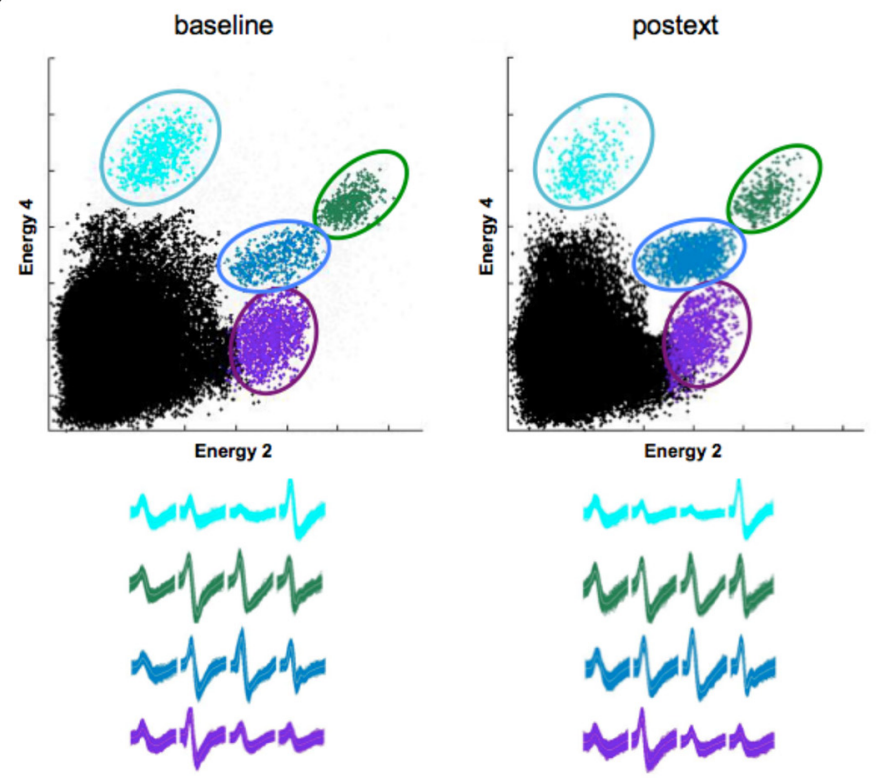

C

․ Extinction

․ Water control

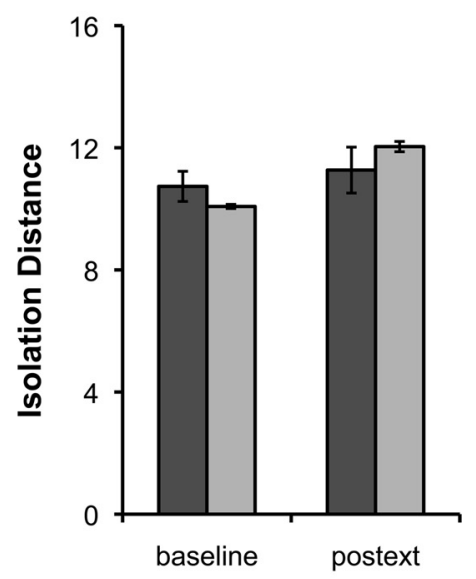

Figure 2. A, Photomicrograph of Nissl-stained coronal section showing position of electrode bundle and schematic coronal sections showing the position of all electrodes in the extinction ( $n=$ $5)$ and control $(n=7)$ groups. $\boldsymbol{B}$, Cluster projections and waveforms recorded during baseline and $24 \mathrm{~h}$ postext showing recording stability. C, Analysis of cluster quality showing no significant differences between the extinction and control group throughout the recording period. Isolation distance, a measure of cluster quality that determines how separated each cluster is from noise and other cells, was computed during baseline and $24 \mathrm{~h}$ postext. For the clusters shown in $\boldsymbol{B}$, isolation distance values are the following: light blue: 11.5, 9.2; green: 14.2, 17.1; blue: 22.3, 23.4; purple: 17.4, 10.4. Bars represent means \pm SEM, ${ }^{*} p<0.05$.

during fear conditioning (Fig. 3D), while others did not respond to either learning process (Fig. $3 E$ ). To more closely examine place cell activity during extinction, we divided the 30 min extinction session into three $10 \mathrm{~min}$ intervals (ext1, ext2, and ext3). Over the course of extinction, we observed that place fields tended to shift gradually (Fig. $4 A, B$ ) and were less stable than those recorded in the water control animals (Fig. 4C,D), which displayed the high stability typically observed during a continuous short-term session (Kentros et al., 2004).

Since only a subset of cells displayed remapping during conditioning and extinction in the extinction animals, we used a remapping threshold to further characterize the trends in the data. This threshold (0.3) was generated by calculating random distributions of pixel-by-pixel cross-correlation values (see Materials and Methods) and coincides with previously reported values for stability in mice (Kentros et al., 2004; Muzzio et al., 2009). Cells with an average correlation below this threshold were considered remapping.

Using this threshold, we found that $45 \%$ of cells remapped during extinction in the experimental group. Among those, 27\% remapped in response to both fear conditioning and extinction, while $18 \%$ remapped predominantly in response to extinction. In 
A

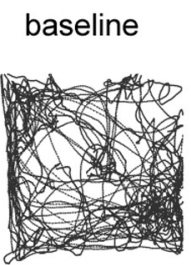

extinction

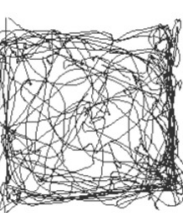

conditioning
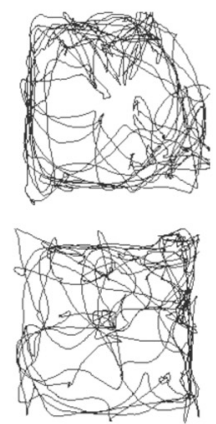

extinction
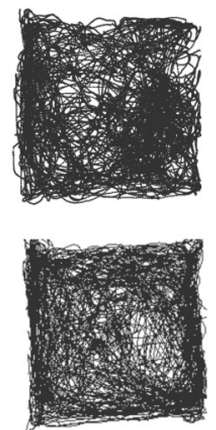

B

Cell \#1
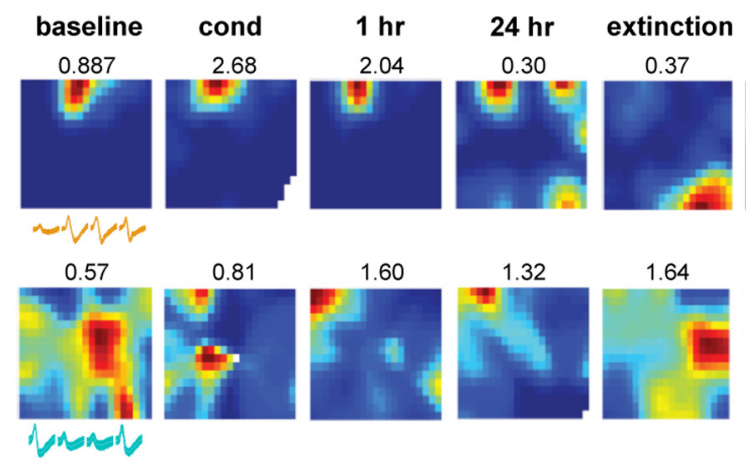

C

Cell \#2

D

Cell \#3

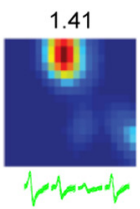

E

Cell \#4

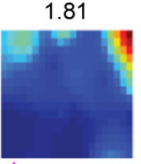

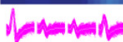
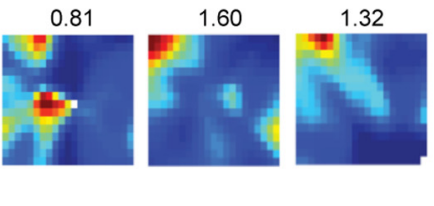

1.64
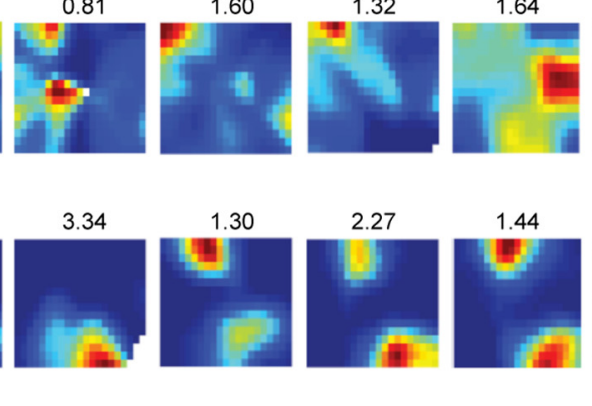

2.78
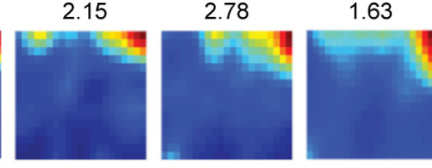

baseline
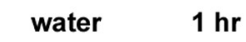

$\mathbf{F}$

Water control
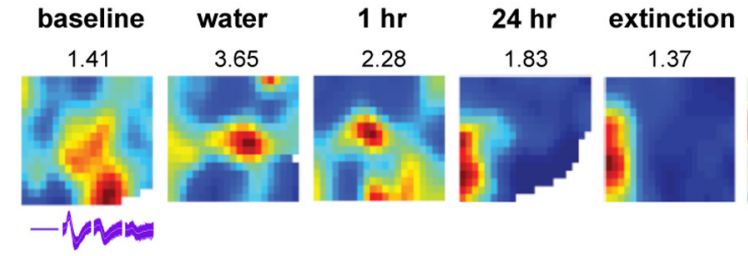

Figure 3. $\boldsymbol{A}$, Example paths from a water control and an extinction animal showing complete sampling of the environment. $\boldsymbol{B}-\boldsymbol{F}$, Examples of place cell rate maps. Activity was normalized relative to the peak firing frequency shown on top of each rate map. Blue represents areas visited by the animal where a particular place cell does not fire, and more vivid colors represent areas of increasing firing activity for that cell. Remapping was observed both during conditioning and the 30 min extinction session, although different cells displayed different phenotypes. $\boldsymbol{B}$, Example cell that exhibits remapping during extinction. $\boldsymbol{C}$, Example cell that remaps during both fear conditioning and extinction. $\boldsymbol{D}$, Example cell that remaps during fear conditioning but remains stable in extinction. $\boldsymbol{E}$, Example cell that remains stable throughout fear and extinction learning (static cell). $\boldsymbol{F}$, Example cell from a water control animal that did not undergo fear conditioning or extinction. Waveforms at the beginning and end of the recording period are shown below each map. The constancy in the waveforms indicates recording stability.

contrast, in the control group, $3 \%$ of cells remapped during both processes, and 6\% remapped mainly during extinction. Additionally, we found that $25 \%$ of cells remapped primarily during fear conditioning in the extinction group, compared with $3 \%$ in the control group. Finally, 30\% of cells in the extinction group remained stable during conditioning and extinction compared postext
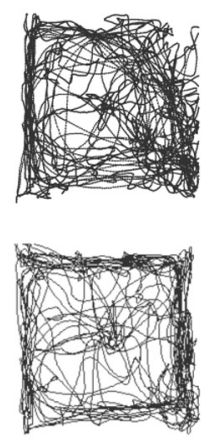

postext

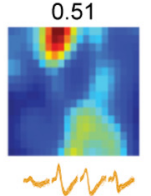

3.37

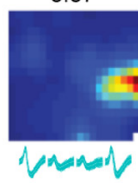

0.66

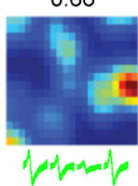

1.95

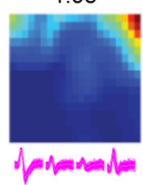

postext

0.70

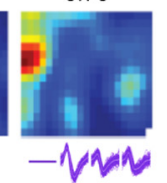

with $88 \%$ of cells in the control group that remained stable during all short-term sessions (Fig. 5A). These data suggest that a subset of cells involved in fear conditioning is also involved in extinction learning (e.g., cells that remap during both learning processes), while other cells that were previously stable throughout conditioning may be recruited specifically for extinction learning (e.g., cells that remap preferentially during extinction). This indicates that extinction learning involves both the modification of previous contextual representations as well as the formation of novel representations.

\section{Fear conditioning and extinction decrease the stability of spatial representations}

To quantify the overall remapping observed during conditioning and extinction, we calculated pixel-by-pixel crosscorrelations between consecutive sessions and averaged across sessions. There was no significant difference between extinction and water control groups for the habituation/baseline (hab/bl) comparison before conditioning, but correlations between consecutive conditioning sessions were significantly lower in the extinction group than in the control group, except for the comparison $1 / 24 \mathrm{~h}$ (effect of group: $F_{(1,118)}=10.563, p<0.002$; effect of session: $F_{(7,567)}=17.116, p<0.001$; effect of interaction: $\left.F_{(7,567)}=2.648, p<0.01\right)$. Post hoc multiple comparisons indicated that the correlation in the extinction group was significantly lower than the control group during conditioning (bl/ cond, cond/1 h, $p<0.05$ ), corroborating our previous finding that conditioning produces short-term remapping (Wang et al., 2012). Additionally, average correlations between the consecutive extinction intervals were significantly lower in the extinction group than the controls $(p<0.05)$. For the $1 / 24 \mathrm{~h}$ comparison, the trend was inverted and came close to statistical significance $(p=0.052)$, showing that after conditioning, the place fields stabilize in animals that reach the learning criterion (Fig. 5B).

We also calculated correlations between the third extinction interval and the first (ext3/ext1) and the third interval and the $24 \mathrm{~h}$ session immediately preceding the extinction session (extinction 3/24 h). Again, place fields were significantly less stable in the extinction group than in the control group for both comparisons (effect of group: $F_{(1,103)}=8.99, p<0.003$; session: $F_{(1,100)}=18.75, p<0.001$; interaction: $F<1$; Fig. $\left.5 C\right)$. It is important to note that on average, the remapping observed during extinction was less robust than the remapping ob- 


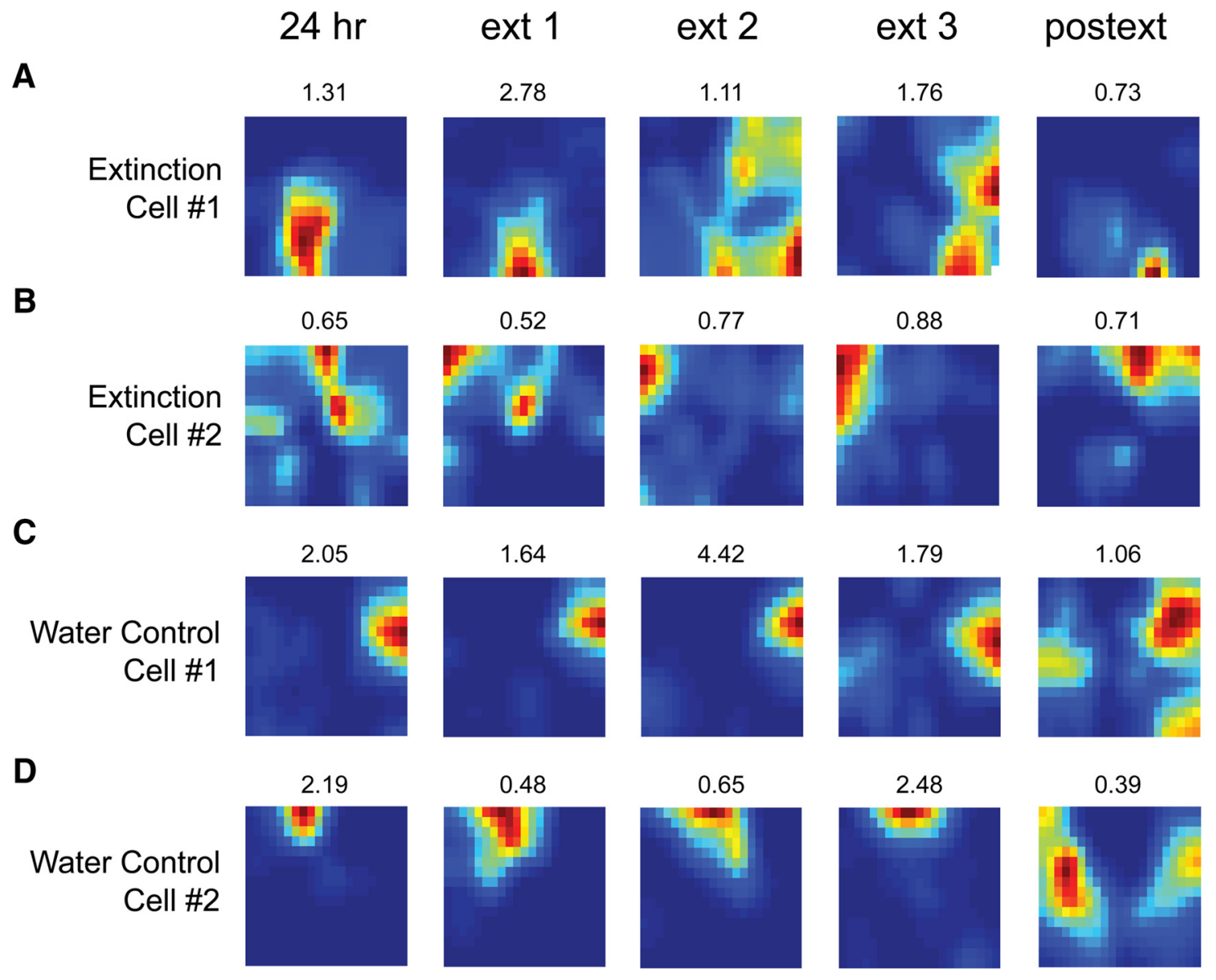

Figure 4. Place cell rate maps showing gradual remapping occurring over the course of the extinction session. Immediately following the $24 \mathrm{~h}$ retention test, the extinction session was divided into three 10 min intervals (ext1, ext2, and ext3). $A, B$, Cells exhibit gradual changes in their preferred firing location over the extinction intervals. Note that in most cases the fields remap further when the animal is tested $24 \mathrm{~h}$ after extinction (postext), suggesting that extinction training brings cells back to their typical long-term remapping state. $\boldsymbol{C}, \boldsymbol{D}$, Remapping was not observed in the water control group during a prolonged exposure to the context. Control cells also exhibited instability in the long term as has been previously shown in mice (Kentros et al., 2004; Muzzio et al., 2009). Peak firing frequency is shown on top of each map.

served during conditioning (mean place field similarity during conditioning: $0.37 \pm 0.03$, extinction: $0.50 \pm 0.02$ ), suggesting that the change in emotional valence of a context during extinction only partially changes the neuronal representation of that context.

Interestingly, the ext 3 and $24 \mathrm{~h}$ postext sessions were significantly less correlated in the extinction group compared with the control group ( $p<0.05$; Fig. $5 B$ ), indicating that the new map formed during extinction does not stabilize but remaps in the long term. To examine this further, we were able to record from 25 cells in three extinction animals during an additional $48 \mathrm{~h}$ postext session. Again, we found low stability compared with the $24 \mathrm{~h}$ postext session, analogous to the correlation between ext 3 and $24 \mathrm{~h}$ postext (mean correlation between $24 \mathrm{~h}$ postext/48 h postext: $0.39 \pm 0.04$, mean correlation between ext $3 / 24 \mathrm{~h}$ postext: $0.38 \pm 0.03 ; p>0.05$; data not shown). The lack of stability observed after extinction contrasts with the long-term stabilization that we previously observed after fear conditioning (Wang et al., 2012). These data suggest that while fear learning results in long-term stabilization of spatial representations, extinction learning returns cells to their inherent long-term instability (Kentros et al., 2004; Muzzio et al., 2009).

We then wanted to determine whether the map formed after extinction was a novel map or resembled a spatial representation from a previous session. Therefore, we calculated correlations between the $24 \mathrm{~h}$ postext session and the baseline, coyote, and $1 \mathrm{~h}$ sessions and found that the similarities between maps were low and not significantly different from the control group (there was no effect of group, $F<1$, nor its interaction with session, $F_{(2,134)}=$ 2.76, $p>0.05$; Fig. $5 D$ ). Similar low correlations with earlier sessions were also evident in the subset of cells that we recorded up to $48 \mathrm{~h}$ postext (mean correlations in extinction group, $48 \mathrm{~h}$ postext/baseline: $0.28 \pm 0.04,48 \mathrm{~h}$ postext/cond: $0.27 \pm 0.04$, $48 \mathrm{~h}$ postext/1 h: $0.26 \pm 0.04$; data not shown). These results suggest that postext representations from both extinction and control animals do not resemble maps from previous sessions. Importantly, since place cell activity was only analyzed during periods of movement and there were no differences in average speed or sampling of the environment between extinction and control groups, our findings indicate that the remapping observed in the extinction group reflects cellular responses to the altered emotional valence of the context.

\section{Aversive nonfearful odors or general arousal do not produce significant place cell remapping}

The observation that some cells remapped only in response to conditioning while others remapped only during extinction introduces the question of whether the cells that remap during coyote exposure are in fact responding in an emotion-dependent manner or merely to the presence of an odor. To address this, we 
A

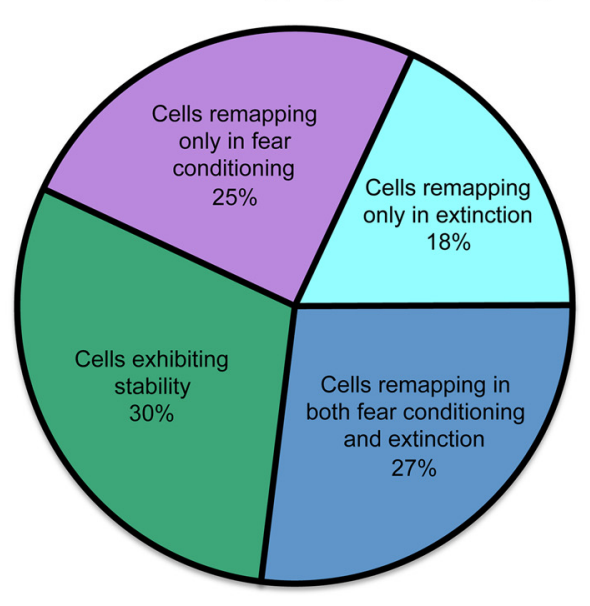

Cells remapping in water control group

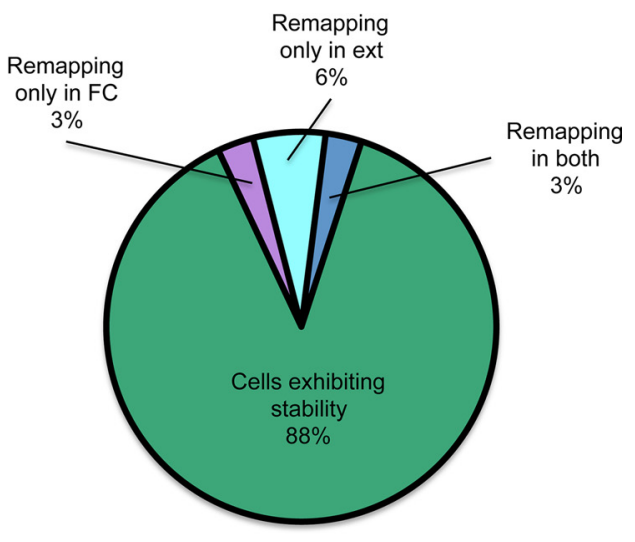

B

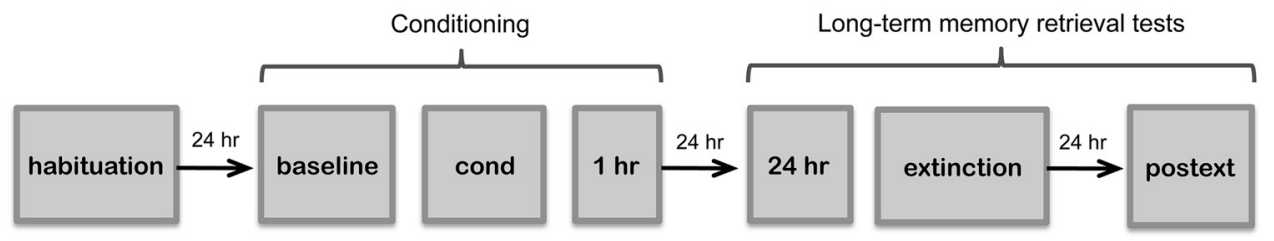

$\square$ Extinction

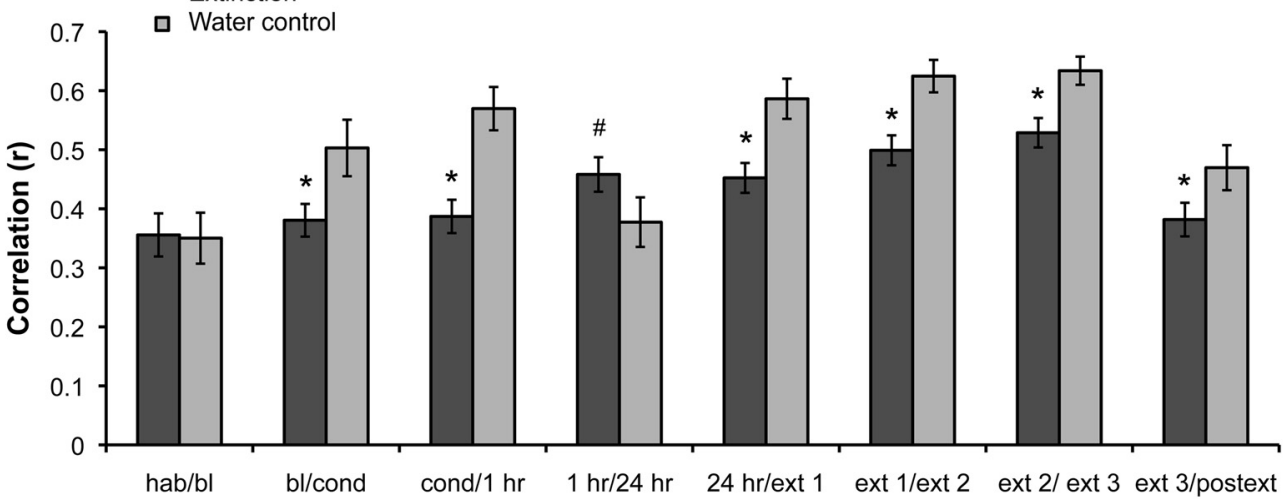

C
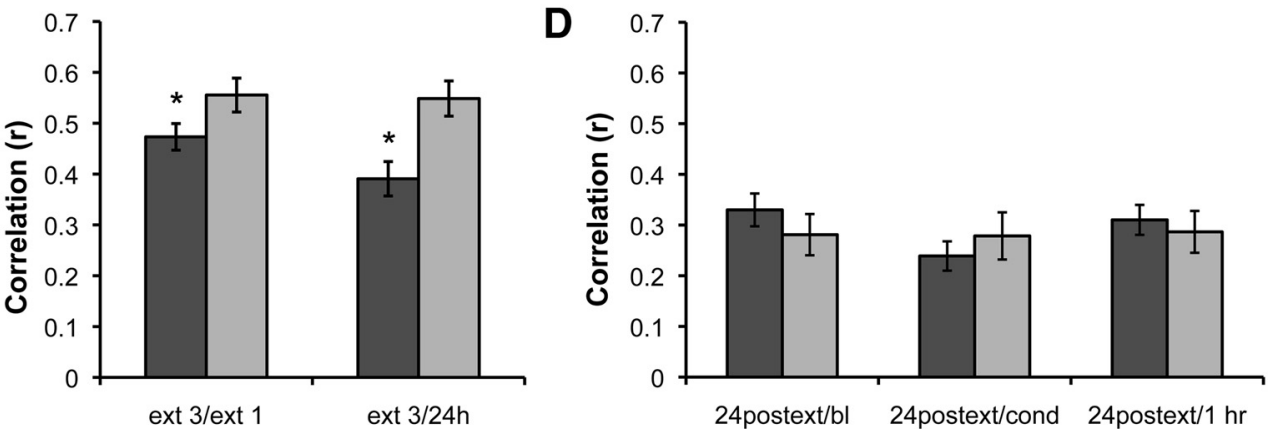

Figure 5. $\boldsymbol{A}$, Pie charts showing percentages of cells remapping or remaining stable during conditioning and extinction in the extinction and water control groups. $\boldsymbol{B}-\boldsymbol{D}$, Pixel-by-pixel cross-correlations between sessions in the extinction and water control groups. $\boldsymbol{B}$, In the extinction group ( $n=5,107$ cells), place fields were significantly less stable during fear conditioning, extinction, and $24 \mathrm{~h}$ after extinction compared with the water control group ( $n=3,40$ cells). $C$, This effect was also observed when comparing the third extinction interval with the first, and when comparing the third extinction interval with the $24 \mathrm{~h}$ session immediately before extinction. $\boldsymbol{D}$, In the extinction and the water control groups, place field maps formed $24 \mathrm{~h}$ after extinction did not resemble previous maps from baseline, fear conditioning, and $1 \mathrm{~h}$ sessions. Bars represent means $\pm \mathrm{SEM},{ }^{*} p<0.05$.

performed a separate experiment in which mice were exposed to water (three animals, 20 cells), coyote urine (seven animals, 46 cells), or 2-MB (three animals, 51 cells), an odor shown to be aversive but not fearful to mice (Kobayakawa et al., 2007; Wang et al., 2013). This experiment was performed in a white environ- ment, following the same context exposure schedule as the conditioning sessions (baseline context exposure, odor presentation, and short-term test session $1 \mathrm{~h}$ later). We found that introduction of 2-MB did not affect short-term place field stability since correlations between sessions were not significantly different from 


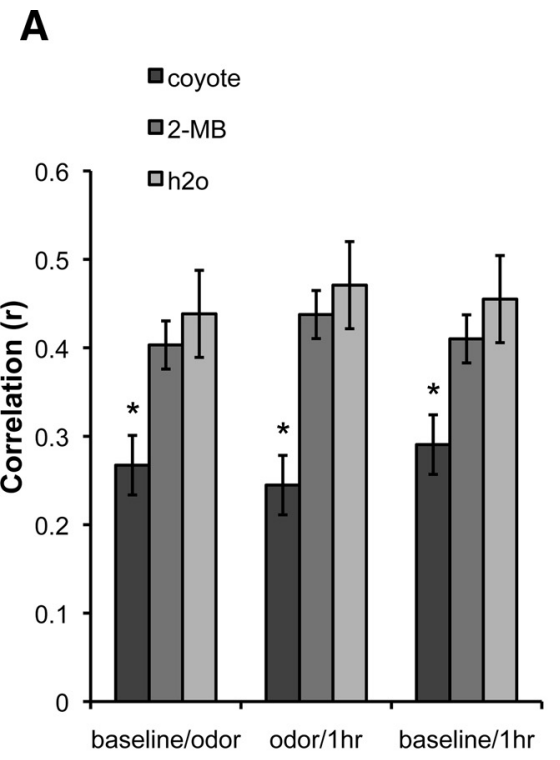

B
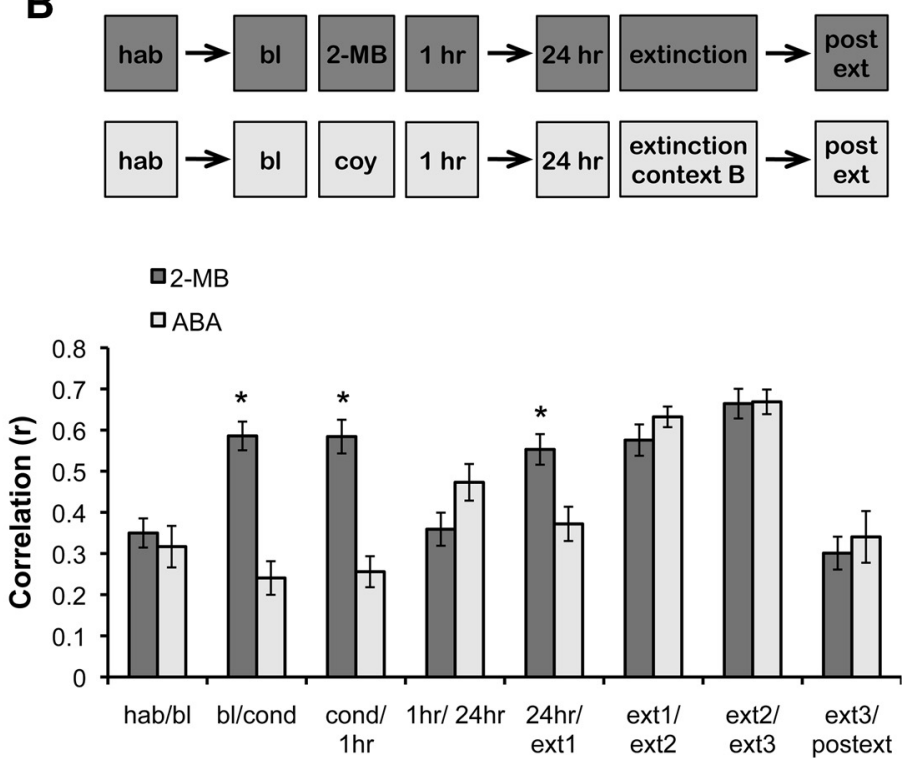

C

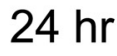

ext 1

ext 2

ext 3

postext

2-MB Control

Cell \#1
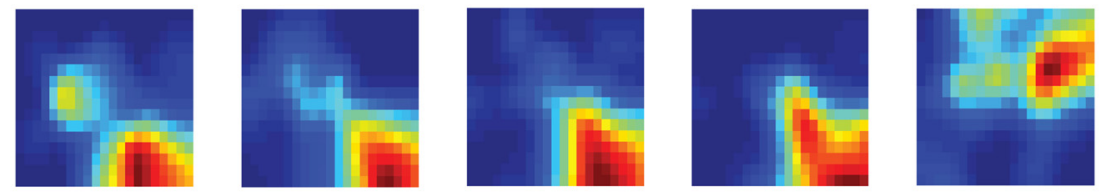

D

1.47

3.69

2.55

2.47

1.77
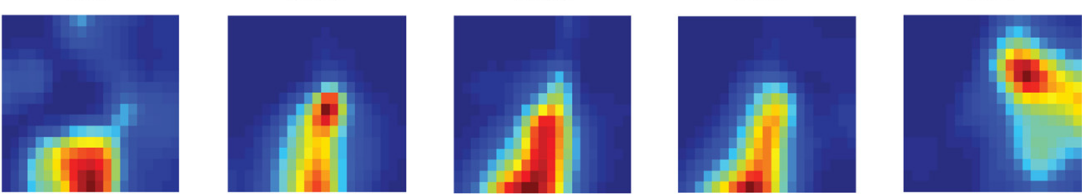

E

2.10

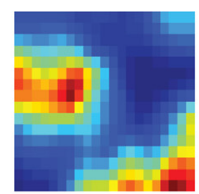

F

ABA Control
Cell \#2
1.49

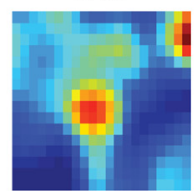

1.73

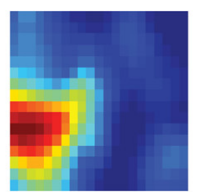

1.68

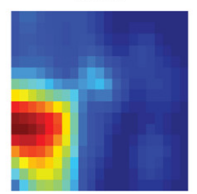

1.30

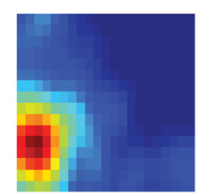

1.35

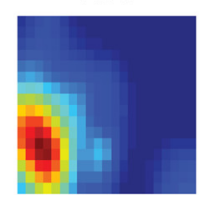

1.57

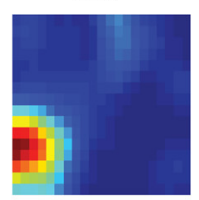

1.40

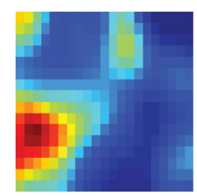

1.34

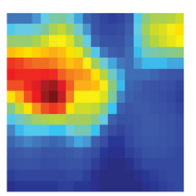

1.84

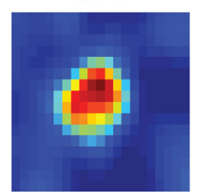

Figure 6. Nonfearful odors or general arousal do not produce remapping. $A$, The effects of coyote urine (fearful; 46 cells from 7 animals), 2-MB (aversive but nonfearful; 51 cells from 3 animals), and water (no odor; 20 cells from 3 animals) were compared by examining the short-term remapping produced when the odor was introduced after the baseline session (baseline/odor), removed $1 \mathrm{~h}$ later (odor/ $\mathrm{h}$ ), and before and after odor exposure (baseline/1 h). Only the fearful odor (coyote urine) produced significant short-term remapping. B, Pixel-by-pixel cross-correlations showing similarity scores across sessions in two groups of control animals. In the 2-MB group (2 animals, 31 cells), animals were trained as the extinction group but exposed to 2-MB during the conditioning session. In the ABA group ( 2 animals, 27 cells), animals were conditioned and tested for retrieval in context A but received extinction in context B. Bars represent means $\pm S E M,{ }^{*} p<0.05$. $\boldsymbol{C}, \boldsymbol{D}$, Rate maps showing example cells trained in the 2-MB group. Note the stability of these cells during all short-term sessions ( $24 \mathrm{~h}$, ext1, ext2, and ext3) but not $24 \mathrm{~h}$ postext. $\boldsymbol{E}, \boldsymbol{F}$, Rate maps showing example cells trained in the ABA group. Note the remapping between $24 \mathrm{~h}$ and ext 1 interval, indicating that the cells responded to the change from context A to context $\mathrm{B}$. However, similarly to the 2-MB group, cells remained stable in context B (e.g., maps formed during ext1, ext2, and ext3). Additional remapping is observed when animals are reintroduced to context A during the postext session. The map retrieved during the postext session resembles the one formed at $24 \mathrm{~h}$, indicating that in the absence of extinction in the training context, spatial representations stabilize in the long term. Peak firing frequency is shown on top of each map. 
A

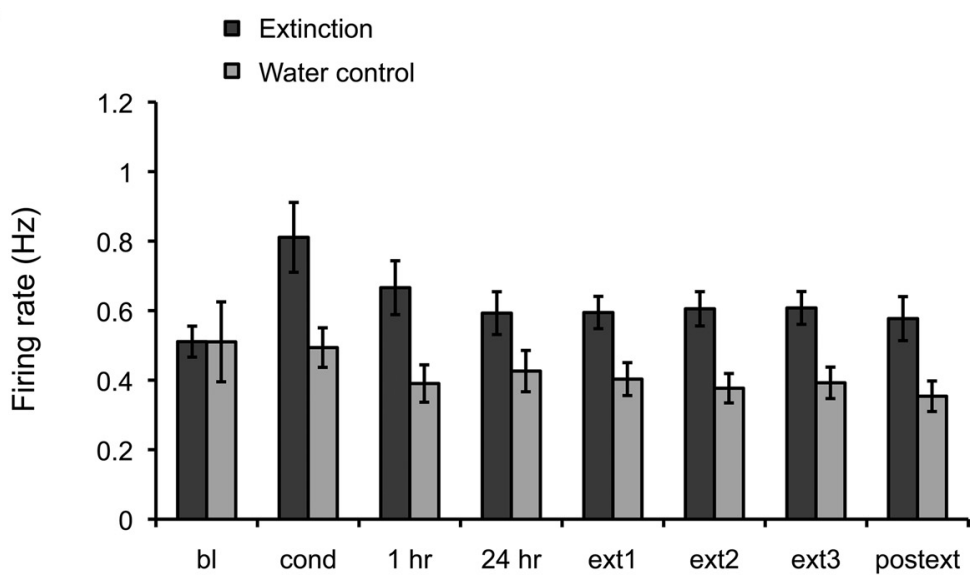

B

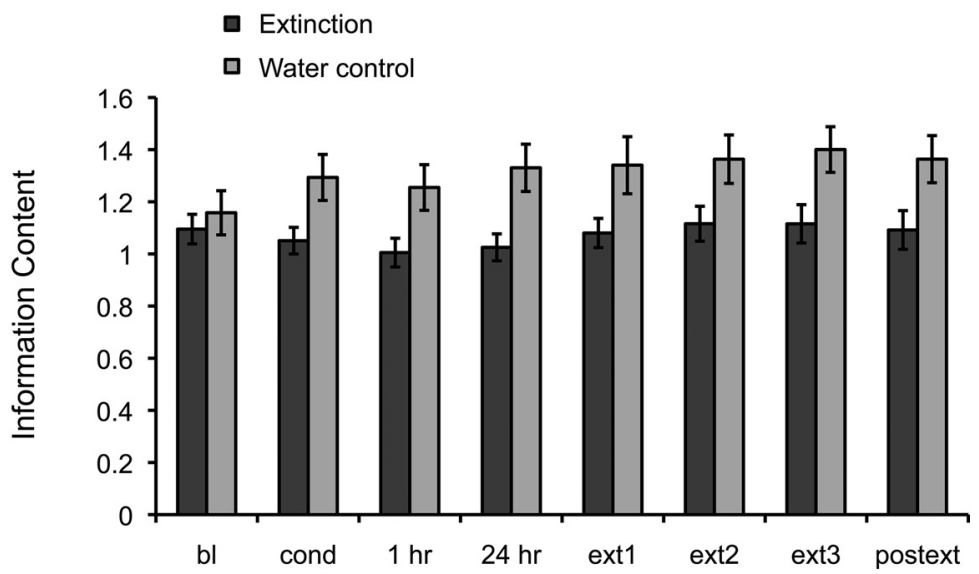

Figure 7. Changes in firing rate and spatial information content during conditioning and extinction. $\boldsymbol{A}$, In extinction animals, mean firing rate was higher than in control animals throughout learning. $\boldsymbol{B}$, Spatial information increases in water control animals after repeated exposures to the context, but remains relatively constant in the extinction group throughout learning (effect of groups $<0.05$ ).

those between presentations of water (Fig. $6 A$ ). These results corroborate previous findings showing that the introduction of neutral odors only produces remapping in a very small number of dorsal cells (Anderson and Jeffery, 2003; Keinath et al., 2014). Conversely, presentation of coyote urine significantly decreased place cell stability compared with the water and 2-MB groups (effect of group: $F_{(2,114)}=10.914, p<0.00001$; session: $F<1$; interaction: $F<1$; post hoc tests indicated coyote odor was significantly different from $2-\mathrm{MB}, p<0.0001$ and water, $p<0.0002$; but there were no significant differences between water and $2-\mathrm{MB}, p>0.05)$. These results indicate that only fearful odors produce significant short-term remapping in the dorsal hippocampus.

Finally, to rule out the possibility that a nonspecific general state of arousal could produce short-term remapping during extinction, we also recorded in the long term from two additional groups of animals following the same schedule as the extinction and water control groups. One group was exposed to 2-MB during the conditioning session to determine whether any potential arousal resulting from exposure to an aversive odor could produce short-term remapping during a prolonged exposure to the context $24 \mathrm{~h}$ after the odor removal. The second group was trained using the ABA design to determine whether a heightened arousal state produced by fear conditioning could result in re- mapping in a neutral context (B) during extinction. We found that only animals trained in the ABA condition displayed short-term remapping during the conditioning sessions, corroborating the finding that 2-MB does not produce significant short-term remapping. Moreover, only the animals in the ABA group displayed place field stability between the 1 and $24 \mathrm{~h}$ sessions, indicating that fear learning stabilized the representations formed after conditioning. Finally, the ABA animals displayed remapping between context $\mathrm{A}$ and context $\mathrm{B}$, which was evident in the comparison between the $24 \mathrm{~h}$ and first extinction (ext1) sessions; however, neither the ABA animals nor the $2-\mathrm{MB}$ mice displayed short-term remapping during extinction (Fig. 6B-F; effect of group: $F_{(1,66)}=7.165, p<0.01$; effect of session: $F_{(7,364)}=24.248, p<$ 0.0001 ; effect of interaction: $F_{(7,364)}=$ $11.058, p<0.0001$; post hoc tests indicated differences between the two groups during bl/cond, cond/ $1 \mathrm{~h}, 1 \mathrm{~h} / 24 \mathrm{~h}$, and 24 $\mathrm{h} /$ ext 1 , but not in habA/blA, ext1/ext2, ext2/ext3, or $24 \mathrm{~h}$ post/ext3). Interestingly, when we compared the representations in the ABA group that formed during the $24 \mathrm{~h}$ and the postext sessions in the training context, we found high longterm stability (Correlation: $0.46 \pm 0.06$ ) as we previously reported (Wang et al., 2012). Together, these results indicate that the cells remapping in response to predator odor conditioning or extinction primarily respond to the emotional aspects of the learning association rather than the presence of the odor itself, or even the aversive nature of the odor.

\section{Changes in emotional valence are associated with increased excitability and reduced spatial information content in hippocampal place cells}

Extinction animals displayed a significant increase in mean firing rate compared with control animals throughout learning (Fig. $7 A$; effect of group: $\left.F_{(1,191)}=6.03, p<0.02\right)$. The same pattern was observed for peak and infield firing rates $\left(F_{(1,191)}=7.98, p<\right.$ 0.005 ; and $F_{(1,191)}=4.96, p<0.03$, respectively, data not shown). We also examined other place field parameters and did not observe significant group differences in mean field size, number of fields, or place field coherence, a measure of place field organization ( $p>0.05$; data not shown). However, we did find significant group differences in spatial information content, a parameter that evaluates how the firing rate of a cell predicts the location of an animal (Skaggs et al., 1993). Although there were no differences between the extinction and control groups during baseline, spatial information content increased in the water control group compared with the extinction group (Fig. $7 B$; effect of group: $\left.F_{(1,191)}=8.64, p<0.004\right)$. This may reflect the fact that the context is perceived as different during distinct stages of fear learning in the extinction group, which in turn may affect the spatial tuning of the place cells. Indeed, these results correlate 
with previous observations in CA1 showing that the spatial tuning of place fields decreases in novel environments and increases with repeated exposures in familiar ones (Karlsson and Frank, 2008). These data suggest that different stages of fear learning may alter the perception of the context, affecting the excitability and tuning of place cells.

\section{Enhanced gamma coherence during extinction correlates with place cell remapping}

Remapping and associated firing rate changes may reflect the manner in which spikes synchronize with local field oscillations. To investigate this possibility, we examined the effects of fear conditioning and extinction on neuronal coherence at the theta $(4-12 \mathrm{~Hz})$ and the low and high gamma frequencies $(30-60$ and $60-80 \mathrm{~Hz}$, respectively). Normalized spectral graphs indicated that there was an enhancement in coherence across sessions in the extinction group compared with the water control group (Fig. $8 A$ ). Analysis of band-binned coherence showed a significant effect of group between the extinction and water control groups in theta coherence (Fig. $8 B ; F_{(1,104)}=4.59, p<0.04$ ) but this effect was not modulated by the session (session: $F_{(6,504)}=1.04, p=$ -0.39 ; interaction between group and session: $F_{(6,504)}=1.74, p=$ 0.11 ). Additionally, we found that low and high gamma coherence were enhanced in the extinction group relative to water control animals and the effect was modulated by the session (Fig. $8 C, D$; low gamma: effect of group $F_{(1,104)}=6.32, p<0.02$; session $F_{(6,508)}=3.46, p<0.002$; interaction $F_{(6,508)}=2.75$, $p<$ 0.02 ; high gamma: effect of group $F_{(1,104)}=3.33, p=0.07$; session $F_{(6,508)}=3.79, p<0.001$; interaction $\left.F_{(6,508)}=3.66, p<0.001\right)$. Specifically, there was a gradual decrease in gamma coherence in the water control animals during repeated exposures to the context, whereas both low and high gamma coherence were significantly enhanced during extinction and postext sessions in the experimental group (low gamma: post hoc multiple comparisons indicated significant effects during extinction $1, p<0.03$; extinction 2, $p<0.02$; extinction $3, p<0.003$; and postext, $p<0.003$; high gamma: post hoc multiple comparisons indicated significant effects during extinction $2, p<0.005$; extinction $3, p<0.02$; and postext, $p<0.03)$. These results suggest that sustained phase locking of spikes to low and high gamma frequencies may play a specific role in fear learning. Interestingly, the place cell remapping we observed $24 \mathrm{~h}$ after extinction corresponded with an enhancement in gamma coherence at this time point, suggesting that neuronal synchronization also increases with the formation of novel representations.

Because of the differential remapping we observed during conditioning and extinction, we next asked whether the degree of remapping could predict the observed changes in theta and gamma coherence. To assess this, we performed correlations between the stability during learning and theta and gamma coherence. Although we observed no overall effect for theta coherence during fear learning (Fig. 9A, $B$, left; Fisher-transformed correlation, conditioning: $r=-0.04, p=0.70$; extinction: $r=-0.05$, $p=0.62$ ), we found that during both conditioning and extinction, stability was inversely correlated with low gamma coherence (Fig. 9A, $B$, middle; Fisher-transformed correlation: conditioning $r=-0.27, p<0.02$; extinction $r=-0.21, p<0.04$ ). Additionally, we found that during extinction but not conditioning, place cell stability was inversely correlated with high gamma coherence (Fig. 9A, $B$, right; Fisher-transformed correlation: conditioning $r=-0.13, p=0.23$; extinction $r=-0.23, p<0.03$ ). Importantly, the results are similar whether the unit of analysis is single cells, sessions, or animals. These data indicate that place cell remapping in response to alterations in the valence of a context correlate with gamma synchronization, although low and high gamma frequencies may differentially affect distinct learning phases. The increase in gamma synchronization may facilitate cross talk with other brain regions.

\section{Discussion}

The idea that extinction is new learning rather than modification of a pre-existing memory is largely based on behavioral findings indicating that the original memory trace re-emerges after extinction training under some conditions (Myers and Davis, 2002; Bouton, 2004). Since extinction is a context-dependent process that requires the hippocampus (Ji and Maren, 2007), this region is thought to regulate the context specificity of extinction by providing contextual gating for the expression of fear after extinction, e.g., contextual renewal of fear memories (Ji and Maren, 2007; Goosens, 2011). Here we characterized for the first time the physiological changes in hippocampal neurons in response to fear extinction. Our findings indicate that extinction is a complex representation that encodes different characteristics of the context. There are hippocampal cells that remap primarily during extinction to form new representations of the context, suggesting that extinction indeed represents new learning. However, other cells remap both during conditioning and extinction, demonstrating that extinction may also modify pre-existing memories. Furthermore, there are cells that remap mainly during conditioning, which may serve to facilitate savings, the reacquisition of the original fear association at a faster rate than initially learned (Napier et al., 1992). Finally, there are cells that remain stable throughout fear learning and may serve to encode the static aspects of the context. We also observed a moderate increase in theta coherence across sessions and a robust enhancement in low and high gamma coherence during extinction. Interestingly, the remapping associated with conditioning and extinction correlates with gamma coherence, suggesting that remapping may serve to amplify task-relevant information through neuronal synchronization. These findings indicate that memory traces of distinct emotional valence coexist in the contextual representation of extinction.

Tronson et al. (2009) previously showed that different populations of principal cells in the hippocampus expressed cFos and pErk after fear conditioning and extinction, respectively, with $<5 \%$ of cells exhibiting colocalization of both proteins. Their results suggest that on the molecular level, fear conditioning and extinction may be mediated by different populations of hippocampal neurons. However, variables such as the length of the extinction protocol may affect the specificity of immediate early gene markers (Radulovic and Tronson, 2010). Therefore, to understand how the hippocampus provides a gating mechanism for conditioning and extinction, it is necessary to record from the same neurons throughout fear learning. Using this approach, our results indicate that while some cells may be involved specifically in fear conditioning or extinction, many cells are involved in forming contextual representations of both learning processes.

It is interesting to note that representations formed after extinction do not stabilize in the long term, in contrast with our previous observation that cells display long-term stability after fear conditioning (Wang et al., 2012). In familiar environments, place fields in mice are generally unstable in the long term in the absence of task contingencies (Kentros et al., 2004; Muzzio et al., 2009). Therefore, it is possible that most cells revert to their original remapping state after fear extinction because the animal no 

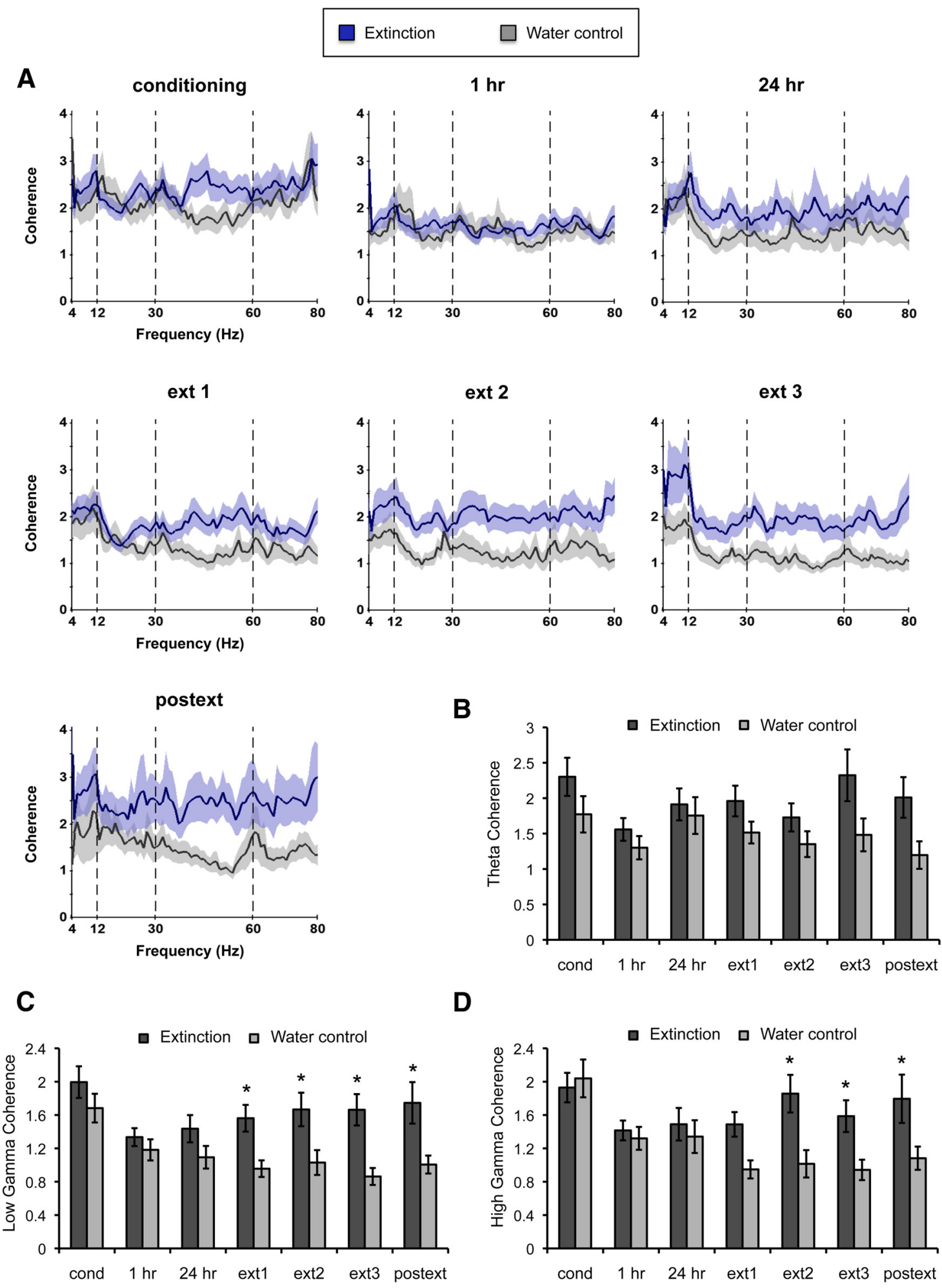

Figure 8. Extinction animals exhibit significantly higher gamma coherence during fear conditioning and extinction. $\boldsymbol{A}$, Spectral graphs showing coherence normalized relative to baseline displaying levels of synchronization across frequencies in the extinction and control animals. Note the sustained level of low and high gamma coherence during extinction in experimental animals compared with water control animals. $\boldsymbol{B}-\boldsymbol{D}$, Histograms showing normalized binned coherence at theta and low and high gamma frequencies. $\boldsymbol{B}$, There was a moderate increase in theta coherence throughout learning in the experimental group. $\boldsymbol{C}, \boldsymbol{D}$, Low $(\boldsymbol{C})$ and high (D) gamma coherence increased during extinction and postext sessions in the experimental animals compared with controls. Bars represent means $\pm \mathrm{SEM},{ }^{*} p<0.05$.

longer needs to remember the context as fearful. Even though extinction eliminates the fear response, the animal likely still remembers the context to some degree, since processes such as spontaneous recovery and savings in the rate of relearning have been demonstrated previously (Pavlov, 1927; Macrae and Kehoe, 1999). It is possible that these processes bring back the original memory by re-establishing prior representations in specific subpopulations of cells. For example, cells that remapped primarily 


\section{A Conditioning sessions}
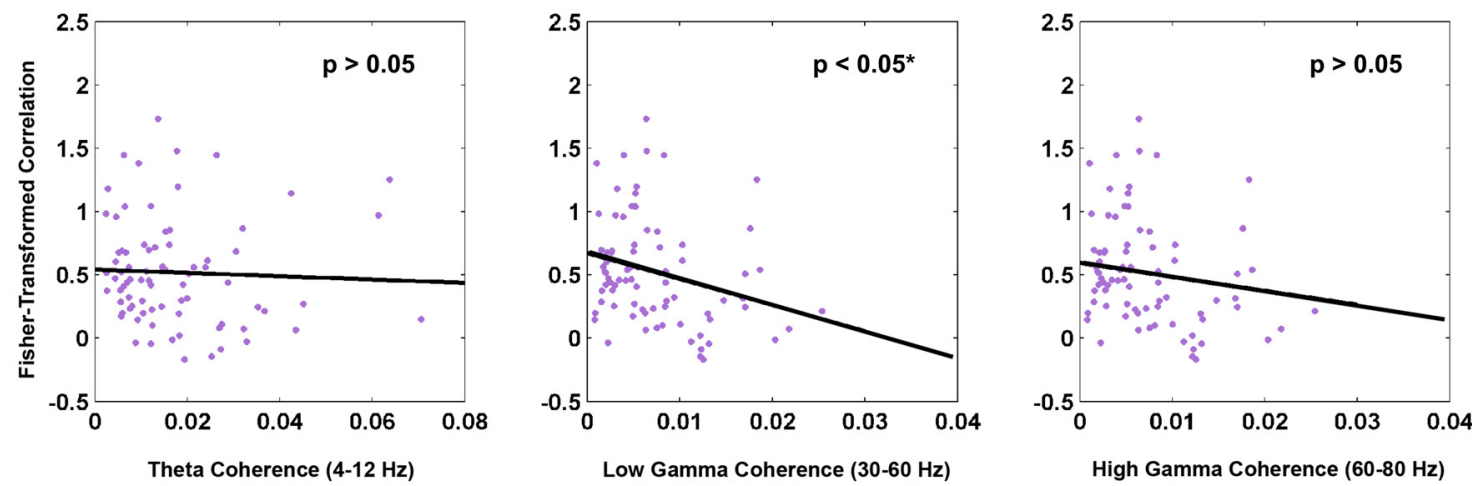

\section{B Extinction sessions}
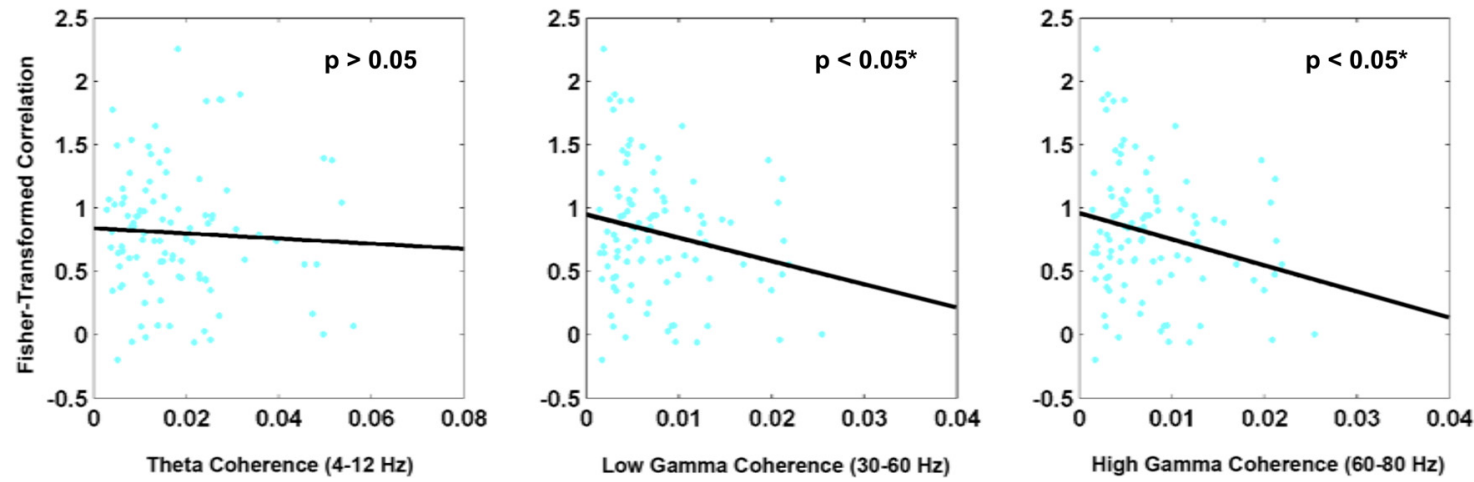

Figure 9. Correlations between stability and theta and gamma coherence. $A$, Correlations during conditioning sessions. The degree of remapping during conditioning did not show significant correlations with theta coherence (left) or high gamma coherence (right). However, it significantly correlated with low gamma coherence (middle). B, Correlations during extinction sessions. The degree of remapping during extinction did not show significant correlations with theta coherence (left). However, it significantly correlated with low (middle) and high (right) gamma coherence.

during conditioning may remap to locations previously associated with fear as the fear response returns.

Regarding the remapping we observed during predator odor fear conditioning, an alternative interpretation of our results is that the observed changes are merely due to the presence or absence of the odor rather than learning-dependent changes in the emotional valence of the context. However, this possibility is unlikely because we also show that an aversive nonfearful odor does not produce significant place field remapping in the short term either during odor exposure or during the extinction session. These results are in agreement with our previous study showing that dorsal place cells do not significantly remap in response to different odors (Keinath et al., 2014) and a previous finding showing that very few cells respond to changes in the odor of a context alone (Anderson and Jeffery, 2003). The absence of substantial remapping in response to nonfearful odors in the dorsal hippocampus may reflect the fact that olfactory inputs project more prominently to the ventral hippocampus (Majak and Pitkänen, 2003; Kerr et al., 2007). Conversely, the remapping observed in response to fearful odors may be mediated through the direct projections from the magnocellular portion of the basolateral amygdala to the dorsal hippocampus, which could serve to convey emotional valence (Pikkarainen et al., 1999).

One intriguing possibility is that the valence-specific cell populations that we identified in this study are differentially connected to other brain regions and circuits governing fear and extinction. For example, studies in the amygdala have found distinct circuits involved in switching fear memories on and off, and hippocampal afferents are directly connected to fear but not ex- tinction cells in the amygdala (Herry et al., 2008). Thus, it is possible that the place cells responding primarily to fear conditioning are the same hippocampal cells that directly or indirectly project to fear cells in the amygdala. Likewise, place cells that remap more strongly during extinction may be indirectly connected via the ventral hippocampus to other regions involved in extinction such as the prefrontal cortex (Hoover and Vertes, 2007). Future studies simultaneously recording units in the dorsal and ventral hippocampus in conjunction with activity in other brain regions will serve to clarify whether distinct subpopulations of place cells show differential synchronization across brain areas during fear and extinction learning.

In this study, the characterization of fear and extinction cells assumes that we recorded from the same cells during conditioning and extinction. Although the nature of extracellular in vivo recordings makes this difficult to prove, several observations support the contention that we indeed held the same cells throughout training. First, we observed waveform constancy for the full duration of the experiment, which suggests minimal electrode drift. Second, we were able to superimpose cluster boundaries across successive sessions. Third, a substantial number of cells in the extinction group and the majority of the cells in the ABA control display long-term stability, suggesting that they were indeed the same cells throughout training. Therefore, we favor the interpretation that we were holding the same cells over time. However, it is important to note that even in the case of electrode drift across days, the analysis of short-term remapping during the extinction session still reveals significant differences between the extinction and control groups. Critically, extinction-induced 
remapping is only seen in fear-conditioned animals undergoing extinction in the training context, and is not present in any of the control groups (i.e., water, 2-MB, or ABA control), indicating that extinction indeed produces instability in a subpopulation of cells. These results clearly demonstrate that some cells respond to the altered valence of the context, a phenomenon that is specific to extinction training.

Previous studies have shown that gamma coherence between brain regions plays an important role in the routing of information (for review, see Fries, 2005; Colgin and Moser, 2010), which may serve to coordinate the reactivation of memories (Carr et al., 2012). In the medial temporal lobe, synchronization at low and high gamma frequencies mediates cross talk between CA3/CA1 and medial entorhinal cortex/CA1 regions, respectively (Colgin et al., 2009). Low gamma coherence has been suggested to play a role in memory encoding, whereas high gamma coherence appears to participate in retrieval (for review, see Colgin and Moser, 2010). In support of this hypothesis, we found that the degree of remapping correlates with low gamma coherence during conditioning, when the fear memory is encoded. Conversely, the degree of remapping correlates with both low and high gamma coherence during extinction, which involves encoding of new safe representations and retrieval of old fearful associations. Additionally, in the visual cortex, phase locking at the gamma frequency band has been suggested to underlie selective attention (Fries et al., 2001; Womelsdorf and Fries, 2007). Therefore, the enhancement in low and high gamma coherence observed during extinction may reflect an attention-like process that allows the animal to determine which emotional representation (i.e., "safe" or "fearful") is relevant during and after extinction. We have previously found a similar enhancement in gamma coherence when animals had to determine whether visual or olfactory cues were relevant to find a hidden reward (Muzzio et al., 2009). It is possible that whenever there is competition between varying information sources, gamma coherence increases the salience of information relevant to the task at hand.

In conclusion, we have demonstrated that neurons in the dorsal hippocampus shift their preferred firing locations in response to fear and extinction learning, and that different subpopulations of cells appear to preferentially encode fearful, safe, and static aspects of a context. Furthermore, we have shown that extinction learning involves both modification of previous memory traces and the emergence of new representations. Finally, the degree of remapping observed during conditioning and extinction correlates with gamma synchronization. These results indicate that extinction is a complex memory trace that integrates several aspects of different emotional valence.

\section{References}

Agnihotri NT, Hawkins RD, Kandel ER, Kentros C (2004) The long-term stability of new hippocampal place fields requires new protein synthesis. Proc Natl Acad Sci U S A 101:3656-3661. CrossRef Medline

Anderson MI, Jeffery KJ (2003) Heterogeneous modulation of place cell firing by changes in context. J Neurosci 23:8827-8835. Medline

Bouton ME (2004) Context and behavioral processes in extinction. Learn Mem 11:485-494. CrossRef Medline

Carr MF, Karlsson MP, Frank LM (2012) Transient slow gamma synchrony underlies hippocampal memory replay. Neuron 75:700-713. CrossRef Medline

Colgin LL, Moser EI (2010) Gamma oscillations in the hippocampus. Physiology 25:319-329. CrossRef Medline

Colgin LL, Denninger T, Fyhn M, Hafting T, Bonnevie T, Jensen O, Moser MB, Moser EI (2009) Frequency of gamma oscillations routes flow of information in the hippocampus. Nature 462:353-357. CrossRef Medline

Corcoran KA, Maren S (2004) Factors regulating the effects of hippocampal inactivation on renewal of conditional fear after extinction. Learn Mem 11:598-603. CrossRef Medline

Corcoran KA, Desmond TJ, Frey KA, Maren S (2005) Hippocampal inactivation disrupts the acquisition and contextual encoding of fear extinction. J Neurosci 25:8978-8987. CrossRef Medline

Ferbinteanu J, Shapiro ML (2003) Prospective and retrospective memory coding in the hippocampus. Neuron 40:1227-1239. CrossRef Medline

Fries P (2005) A mechanism for cognitive dynamics: neuronal communication through neuronal coherence. Trends Cogn Sci 9:474-480. CrossRef Medline

Fries P, Reynolds JH, Rorie AE, Desimone R (2001) Modulation of oscillatory neuronal synchronization by selective visual attention. Science 291: 1560-1563. CrossRef Medline

Goosens KA (2011) Hippocampal regulation of aversive memories. Curr Opin Neurobiol 21:460-466. CrossRef Medline

Gothard KM, Skaggs WE, Moore KM, McNaughton BL (1996) Binding of hippocampal CA1 neural activity to multiple reference frames in a landmark-based navigation task. J Neurosci 16:823-835. Medline

Harris KD, Hirase H, Leinekugel X, Henze DA, Buzsáki G (2001) Temporal interaction between single spikes and complex spike bursts in hippocampal pyramidal cells. Neuron 32:141-149. CrossRef Medline

Herry C, Ciocchi S, Senn V, Demmou L, Müller C, Lüthi A (2008) Switching on and off fear by distinct neuronal circuits. Nature 454:600-606. CrossRef Medline

Hoover WB, Vertes RP (2007) Anatomical analysis of afferent projections to the medial prefrontal cortex in the rat. Brain Struct Funct 212:149-179. CrossRef Medline

Ji J, Maren S (2005) Electrolytic lesions of the dorsal hippocampus disrupt renewal of conditional fear after extinction. Learn Mem 12:270-276. CrossRef Medline

Ji J, Maren S (2007) Hippocampal involvement in contextual modulation of fear extinction. Hippocampus 17:749-758. CrossRef Medline

Karlsson MP, Frank LM (2008) Network dynamics underlying the formation of sparse, informative representations in the hippocampus. J Neurosci 28:14271-14281. CrossRef Medline

Keinath AT, Wang ME, Wann EG, Yuan RK, Dudman JT, Muzzio IA (2014) Precise spatial coding is preserved along the longitudinal hippocampal axis. Hippocampus 24:1533-1548. CrossRef Medline

Kentros C, Hargreaves E, Hawkins RD, Kandel ER, Shapiro M, Muller RV (1998) Abolition of long-term stability of new hippocampal place cell maps by NMDA receptor blockade. Science 280:2121-2126. CrossRef Medline

Kentros CG, Agnihotri NT, Streater S, Hawkins RD, Kandel ER (2004) Increased attention to spatial context increases both place field stability and spatial memory. Neuron 42:283-295. CrossRef Medline

Kerr KM, Agster KL, Furtak SC, Burwell RD (2007) Functional neuroanatomy of the parahippocampal region: the lateral and medial entorhinal areas. Hippocampus 17:697-708. CrossRef Medline

Kobayakawa K, Kobayakawa R, Matsumoto H, Oka Y, Imai T, Ikawa M, Okabe M, Ikeda T, Itohara S, Kikusui T, Mori K, Sakano H (2007) Innate versus learned odour processing in the mouse olfactory bulb. Nature 450:503-508. CrossRef Medline

Macrae M, Kehoe EJ (1999) Savings after extinction in conditioning of the rabbit's nictitating membrane response. Psychobiology 27:85-94.

Majak K, Pitkänen A (2003) Projections from the periamygdaloid cortex to the amygdaloid complex, the hippocampal formation, and the parahippocampal region: a PHA-L study in the rat. Hippocampus 13:922-942. CrossRef Medline

Mamiya N, Fukushima H, Suzuki A, Matsuyama Z, Homma S, Frankland PW, Kida S (2009) Brain region-specific gene expression activation required for reconsolidation and extinction of contextual fear memory. J Neurosci 29:402-413. CrossRef Medline

Maxwell SE, Delaney HD (2004) Designing experiments and analyzing data, Ed 2. Hillsdale, NJ: Lawrence Erlbaum Associates.

McCulloch CE, Searle SR (2001) Generalized, linear, and mixed models. New York: Wiley.

Moita MA, Rosis S, Zhou Y, LeDoux JE, Blair HT (2004) Putting fear in its place: remapping of hippocampal place cells during fear conditioning. J Neurosci 24:7015-7023. CrossRef Medline

Muzzio IA, Levita L, Kulkarni J, Monaco J, Kentros C, Stead M, Abbott LF, Kandel ER (2009) Attention enhances the retrieval and stability of visu- 
ospatial and olfactory representations in the dorsal hippocampus. PLoS Biol 7:e1000140. CrossRef Medline

Myers KM, Davis M (2002) Behavioral and neural analysis of extinction. Neuron 36:567-584. CrossRef Medline

Napier RM, Macrae M, Kehoe EJ (1992) Rapid reacquisition in conditioning of the rabbit's nictitating membrane response. J Exp Psychol Anim Behav Process 18:182-192. CrossRef Medline

O'Keefe J, Dostrovsky J (1971) The hippocampus as a spatial map. Preliminary evidence from unit activity in the freely-moving rat. Brain Res 34: 171-175. CrossRef Medline

O'Keefe J, Nadel L (1978) The hippocampus as a cognitive map. Oxford, UK: Oxford UP.

Pavlov IP (1927) Conditioned reflexes: London: Oxford UP.

Pikkarainen M, Rönkkö S, Savander V, Insausti R, Pitkänen A (1999) Projections from the lateral, basal, and accessory basal nuclei of the amygdala to the hippocampal formation in rat. J Comp Neurol 403:229-260. CrossRef Medline

Radulovic J, Tronson NC (2010) Molecular specificity of multiple hippocampal processes governing fear extinction. Rev Neurosci 21:1-17. CrossRef Medline

Ranck JB Jr (1973) Studies on single neurons in dorsal hippocampal formation and septum in unrestrained rats. I. Behavioral correlates and firing repertoires. Exp Neurol 41:461-531. CrossRef Medline

Rotenberg A, Mayford M, Hawkins RD, Kandel ER, Muller RU (1996) Mice expressing activated CaMKII lack low frequency LTP and do not form stable place cells in the CA1 region of the hippocampus. Cell 87:13511361. CrossRef Medline

Rotenberg A, Abel T, Hawkins RD, Kandel ER, Muller RU (2000) Parallel instabilities of long-term potentiation, place cells, and learning caused by decreased protein kinase A activity. J Neurosci 20:8096-8102. Medline

Schmitzer-Torbert N, Jackson J, Henze D, Harris K, Redish AD (2005)
Quantitative measures of cluster quality for use in extracellular recordings. Neuroscience 131:1-11. CrossRef Medline

Skaggs WE, McNaughton BL, Gothard KM, Markus EJ (1993) An information-theoretic approach to deciphering the hippocampal code. In Neural information processing systems (Hanson SJ, Cowan JD, Giles CL), pp 1030-1037. San Francisco: Morgan Kaufman.

Suzuki A, Josselyn SA, Frankland PW, Masushige S, Silva AJ, Kida S (2004) Memory reconsolidation and extinction have distinct temporal and biochemical signatures. J Neurosci 24:4787-4795. CrossRef Medline

Tronson NC, Schrick C, Guzman YF, Huh KH, Srivastava DP, Penzes P, Guedea AL, Gao C, Radulovic J (2009) Segregated populations of hippocampal principal CA1 neurons mediating conditioning and extinction of contextual fear. J Neurosci 29:3387-3394. CrossRef Medline

Wang ME, Wann EG, Yuan RK, Ramos Álvarez MM, Stead SM, Muzzio IA (2012) Long-term stabilization of place cell remapping produced by a fearful experience. J Neurosci 32:15802-15814. CrossRef Medline

Wang ME, Fraize NP, Yin L, Yuan RK, Petsagourakis D, Wann EG, Muzzio IA (2013) Differential roles of the dorsal and ventral hippocampus in predator odor contextual fear conditioning. Hippocampus 23:451-466. CrossRef Medline

Womelsdorf T, Fries P (2006) Neuronal coherence during selective attentional processing and sensory-motor integration. J Physiol Paris 100:182193. CrossRef Medline

Womelsdorf T, Fries P (2007) The role of neuronal synchronization in selective attention. Curr Opin Neurobiol 17:154-160. CrossRef Medline

Zinyuk L, Kubik S, Kaminsky Y, Fenton AA, Bures J (2000) Understanding hippocampal activity by using purposeful behavior: place navigation induces place cell discharge in both task-relevant and task-irrelevant spatial reference frames. Proc Natl Acad Sci U S A 97:3771-3776. CrossRef Medline 